\title{
Numerical modelling of unsteady transport and entropy generation in oxy-combustion of single coal particles with varying flow velocities and oxygen concentrations
}

\author{
Linwei Wang ${ }^{\text {a }}$, Nader Karimi ${ }^{\text {la }}$, Tata Sutardi ${ }^{\mathrm{a}}$, Manosh C Paul ${ }^{\mathrm{a}}$ \\ ${ }^{a}$ Systems, Power \& Energy, School of Engineering, University of Glasgow, Glasgow G12 8QQ, United \\ Kingdom
}

\begin{abstract}
Unsteady generation of entropy and transfer of heat and chemical species in the transient oxy-combustion of a single coal particle are investigated numerically. The burning process takes place in oxygen and nitrogen atmospheres with varying chemical compositions and under either quiescent or active flows. The combustion simulations are validated against the existing experimental data on a single coal particle burning in a drop-tube reactor. The spatio-temporal evolutions of the gas-phase temperature and major gaseous species concentration fields as well as that of entropy generation are investigated for the two types of gas flow. It is shown that the rates of production and transport of chemical species reach their maximum level during the homogenous combustion of volatiles and decay subsequently. Yet, the transient transfer of heat of combustion continues for a relatively long time after the termination of particle life time. This results in the generation of a large amount of thermal entropy at post-combustion stage. The analyses further indicate that the entropy generated by the chemical reactions is the most significant source of unsteady irreversibilities. Most importantly, it is demonstrated that a slight oxygenation of the atmosphere leads to major increases in the total chemical entropy generation and, thus it significantly intensifies the global irreversibilities of the process. However, upon exceeding a certain mole fraction of oxygen in the atmosphere, further addition of oxygen only causes minor increases in entropy generation. This trend is observed consistently in both quiescent and active flow cases.
\end{abstract}

Keywords: Transient heat and mass transfer; Unsteady entropy generation; Coal particle combustion; Spatiotemporal evolution; Oxy-combustion; Varying oxygen concentration.

\begin{tabular}{|c|c|c|c|}
\hline \multicolumn{4}{|c|}{ Nomenclature } \\
\hline$A$ & pre-exponential factor & $\vec{S}$ & entropy flux vector \\
\hline$A_{p}$ & particle surface area, $m^{2}$ & $s$ & specific entropy, $J / \mathrm{kmol} \cdot K$ \\
\hline$a_{1}, a_{2}, a_{3}$ & constants & $s_{b}$ & $\begin{array}{l}\text { Stefan-Boltzmann constant } \\
5.67032 \times 10^{-8} \mathrm{~W} / \mathrm{m}^{2} \cdot \mathrm{K}^{4}\end{array}$ \\
\hline$C_{D}$ & drag coefficient & $T$ & temperature, $K$ \\
\hline$C$ & Concentration, $\mathrm{kmol} / \mathrm{m}^{3}$ & $t$ & time, $s$ \\
\hline$c_{p}$ & specific heat capacity, $\mathrm{J} / \mathrm{kg} \cdot K$ & $t_{t}$ & effective time of entropy generation, $s$ \\
\hline$D_{i j}$ & $\begin{array}{l}\text { binary diffusion coefficient for the } i- \\
j \text { species pair, } m^{2} / s\end{array}$ & $u$ & velocity, $m / s$ \\
\hline$D_{T, i}$ & $\begin{array}{l}\text { thermal diffusion coefficient for the } \\
i^{\text {th }} \text { species, } \mathrm{m}^{2} / \mathrm{s}\end{array}$ & $\vec{u}$ & velocity vector \\
\hline$D_{i m}$ & $\begin{array}{l}\text { effective diffusion coefficient of } \\
\text { species } i, \mathrm{~m}^{2} / \mathrm{s}\end{array}$ & $\vec{V}$ & diffusion velocity of the $i^{t h}$ species \\
\hline$d$ & diameter, $m$ & $X$ & mole fraction \\
\hline$F_{d}$ & drag force, $N$ & $Y$ & mass fraction \\
\hline$f_{h}$ & $\begin{array}{l}\text { fraction of heat absorbed by the } \\
\text { particle }\end{array}$ & & \\
\hline$\vec{f}_{l}$ & body force per unit mass & Gre & nbols \\
\hline$H$ & enthalpy, $\mathrm{J} / \mathrm{kmol}$ & $\alpha$ & distribution coefficient of volatile in coal \\
\hline$H_{r e a c_{c r}}$ & enthalpy of reaction $\mathrm{cr}, \mathrm{J} / \mathrm{kmol}$ & $\mu_{m}$ & viscosity, $\mathrm{kg} / \mathrm{m} \cdot \mathrm{s}$ \\
\hline$h$ & specific enthalpy, $J / \mathrm{kmol}$ & $\mu_{c}$ & specific chemical potential, $\mathrm{J} / \mathrm{kg}$ \\
\hline$h_{f g}$ & latent heat of devolatilization, $\mathrm{J} / \mathrm{kg}$ & $\mu_{o}$ & molecular viscosity, $\mathrm{kg} / \mathrm{m} \cdot \mathrm{s}$ \\
\hline
\end{tabular}

${ }^{1}$ Corresponding author: Nader.Karimi@glasgow.ac.uk 


\begin{tabular}{|c|c|c|c|}
\hline$h^{\prime}$ & enthalpy of mixture, $\mathrm{J} / \mathrm{kmol}$ & $\lambda$ & thermal conductivity, $\mathrm{W} / \mathrm{m} \cdot \mathrm{K}$ \\
\hline$g_{x}$ & acceleration gravity, $\mathrm{m} / \mathrm{s}^{2}$ & $\rho$ & density, $\mathrm{kg} / \mathrm{m}^{3}$ \\
\hline$J_{i, j}$ & molecular mass flux & $\omega_{i}$ & $\begin{array}{l}\text { rate of species } i \text { mass production per unit } \\
\text { volume }\end{array}$ \\
\hline$K$ & reaction rate, $\mathrm{kmol} / \mathrm{m}^{3} \cdot \mathrm{s}$ & $\varepsilon_{p}$ & particle emissivity \\
\hline$k$ & reaction rate constant, $\mathrm{kmol} / \mathrm{m}^{3} \cdot \mathrm{s}$ & $\theta_{R}$ & radiation temperature, $K$ \\
\hline$M$ & molecular weight, $\mathrm{kg} / \mathrm{mol}$ & $\sigma$ & $\begin{array}{l}\text { Rate of entropy generation per unit volume, } \\
W / m^{3} K\end{array}$ \\
\hline $\bar{M}$ & average molecular weight, $\mathrm{kg} / \mathrm{kmol}$ & $\Phi$ & viscous dissipation \\
\hline$m$ & mass, $k g$ & & \\
\hline$N$ & number of chemical species & \multicolumn{2}{|c|}{ Subscripts } \\
\hline$N u$ & Nusselt number & $i$ & $i^{\text {th }}$ species \\
\hline$p$ & pressure, $P a$ & $j$ & indices: $1,2, \ldots, \mathrm{N}$ \\
\hline$Q_{r}$ & $\begin{array}{l}\text { internal production rate for thermal } \\
\text { energy, } J / s\end{array}$ & $g$ & gas \\
\hline$q_{j}$ & energy flux & $p$ & particle \\
\hline$\vec{q}$ & heat-flux vector & $R$ & reactant \\
\hline $\overrightarrow{q_{R}}$ & radiant heat-flux vector & $o x$ & oxidant \\
\hline$R e$ & Reynolds number & $r g$ & gaseous reactants \\
\hline$R u$ & universal gas constant, $\mathrm{kg} / \mathrm{kmol}$ & $X$ & composition of chemical element $\mathrm{H}$ \\
\hline$R_{i}$ & $\begin{array}{l}\text { net rate of production of species } i \text { due } \\
\text { to chemical reactions, } \mathrm{kg} / \mathrm{m}^{3} \cdot \mathrm{s}\end{array}$ & $Y$ & composition of chemical element $\mathrm{O}$ \\
\hline$E$ & entropy generation rate, $W / K$ & $x, r$ & coordinates \\
\hline$E_{a}$ & active energy, $\mathrm{J} / \mathrm{kmol}$ & \multicolumn{2}{|c|}{ Superscripts } \\
\hline$E_{h}$ & $\begin{array}{l}\text { rate of entropy generation duo to heat } \\
\text { transfer, } W / K\end{array}$ & 0 & reference state \\
\hline$E_{m}$ & $\begin{array}{l}\text { rate of entropy generation duo to mass } \\
\text { transfer, } W / K\end{array}$ & $a$ & oxygen reaction order \\
\hline$E_{r}$ & $\begin{array}{l}\text { rate of entropy generation duo to } \\
\text { chemical reactions, } W / K\end{array}$ & $b$ & temperature exponent \\
\hline$E^{\prime}$ & Global entropy generation rate, $W / K$ & $d$ & reaction order \\
\hline$s_{E}$ & $\begin{array}{l}\text { effective area of entropy generation, } \\
m^{2}\end{array}$ & $e$ & reaction order \\
\hline
\end{tabular}

\section{Introduction}

Coal is expected to remain amongst the main source of energy in the foreseeable future [1]. Nonetheless, conventional combustion of coal results in a high level of $\mathrm{CO}_{2}$ emission. It is, therefore, essential to apply carbon capture technologies to coal combustion. Oxy-coal combustion is a well-demonstrated technology capable of facilitating carbon capture and storage, which mainly includes combustion in $\mathrm{O}_{2} / \mathrm{CO}_{2}$ [2][3] and $\mathrm{O}_{2} / \mathrm{H}_{2} \mathrm{O}$ atmospheres [4]. Although capturing of carbon dioxide from coal fired power stations substantially reduces their greenhouse gas emissions, it adversely affects their thermal efficiency [3]. This calls for an evaluation of the energetic and exergetic efficiencies of oxy-combustion power stations. It is therefore imperative to obtain a clear understanding of the sources of energy and exergy losses in these systems. Combustion process in power stations is generally known to be a major source of exergy destruction [5][6]. However, the influences of oxy-coal combustion upon destruction of exergy are still largely unknown. Addressing this issue warrants further fundamental studies of entropy generation during oxy-combustion of coal, which inevitably include detailed analyses of heat and mass transfer. In response to this, the current work performs a numerical investigation on the transient transport of heat and mass transfer and unsteady generation of entropy during combustion of a single coal particle in different gaseous atmospheres.

High complexity of pulverised and fluidised bed coal combustion [7] has led to an interest in analysing transient combustion of single coal particle, e.g. [8][9]. Such studies allow for the development of fundamental 
understanding of the underlying physicochemical processes in coal particle combustion. The existing studies of single coal particle combustion are mostly experimental and concerned with particle temperature and ignition delays, e.g. [10][11][12][13], and formation of air pollutants [14][15][16]. The former involved optical measurements of the particle temperature, while the latter focused on the analysis of combustion products. None of these, however, provides any information on the scalar fields in the gaseous environment surrounding the particle. Exceptions to this are a few recent works that applied high speed, planar laser diagnostics to the problem of transient coal combustion [17][18]. However, these measurements are limited to a small number of radicals and thus obtaining experimental data on the unsteady temperature and species concentration fields has remained unachievable. The significance of such data stems from the fact that the spatio-temporal evolutions of the temperature and concentration fields dominate the unsteady rate of entropy generation [19][20][21] and also influence formation of the air pollutants.

In the absence of experimental studies, numerical simulations are the only practical way of predicting the transient scaler fields in coal particle combustion [22][23]. Oxy-combustion of pulverised coal has been already subject to extensive numerical simulations, see for example [2][24][25]. For conciseness reasons, here only those works focusing on the gas phase transport are discussed. Collections of burning coal particles have been investigated numerically to explore the influences of thermal radiation [26] and char conversion process [22]. The former considered the effects of gaseous atmosphere upon the thermal radiation [26], while the latter included two phase calculations mutilating a discrete phase model [21]. Through direct numerical simulations, Chabane et al. [27] examined the unsteady, multicomponent gaseous flow in the vicinity of a carbonaceous reactive surface. These authors considered several homogeneous and heterogeneous reactions and analysed the interactions between these two groups. They also identified the transitions from oxidation to gasification regimes [27]. The work of Chabane et al. further explored the contribution of Soret and Dufour effects upon the transfer of heat and mass in the investigated configuration [27]. A detailed numerical simulation of single coal particle devolatilisation and ignition was conducted by Tufano et al. [28]. An extensive set of homogenous chemical reactions in a laminar flow was considered in this study. The influences of enhanced oxygen levels mixed with either nitrogen or carbon dioxide on the particle ignition and flame development were investigated [28]. Amongst the other findings, Tufano et al. highlighted the importance particle preheating and Reynolds number in determining the value of ignition delay [28].

Although combustion characteristics of single coal particles in oxygenated media have been investigated to some extent, the thermodynamics of this problem have received little attention. As a matter of fact, the thermodynamic irreversibilities associated with the more general problems of particle and droplet combustion are still largely unexplored. This shortage of studies is expected to be mainly due to the multiphase and transient nature of particle and droplet combustion, which makes the transport and thermodynamic analyses complicated. The limited literature in this area is reviewed in the followings.

In the early nineties, Puri calculated theoretically the entropy generation during combustion of a droplet [29]. In this work, the optimised size of the droplet and the velocity of gaseous atmosphere were found [29]. In another pioneering work, Dash and Som examined the transient combustion of a single liquid droplet in a convective atmosphere [30]. They numerically solved the unsteady governing equations together with a single step chemical reaction [30]. The results revealed the temperature distribution and convection coefficients around the droplet and also predicted the time trace of entropy generation in the course of transient burning process [30]. The work of 
Dash and Som was subsequently extended to droplet burning in quiescent gas [31]. It was shown that the initial temperature ratio of the droplet and the atmosphere and also the initial Damköhler number are the key parameters governing the destruction of exergy in droplet combustion [31]. More recently, entropy generation was calculated in quasi-steady combustion of a droplet [32]. It was demonstrated that generations of entropy through chemical and thermal mechanisms are rather similar [32]. Further, the work in Ref. [32] showed that an increase in the ambient temperature and particle diameter reduces the entropy generation rate. In a theoretical and numerical study, Pope et al. [33] investigated gas-phase entropy generation in the transient combustion of methanol droplets. In this work, stationary droplet combustion in a low temperature, nearly quiescent environment and also moving droplet in preheated atmospheres were examined [33]. The results indicated that by increasing the initial Reynolds number generation of entropy by transfer of heat and mass decreases. However, irreversibilities generated by chemical reactions are intensified [33]. Similar to that shown in single-phase reactive flows, Pope et al. [33] demonstrated that the chemical and thermal irreversibilities dominate the generation of entropy, while the contribution of mass transfer is negligible.

Calculation of entropy generation in solid fuel combustion is restricted to a few investigations on coal and biomass combustion. On the basis of the numerical analyses of a pulverised coal combustor, Som et al. [34] developed an exergy balance for the reactive system under steady state. Mondal et al. [35] constructed a model of transport phenomena and entropy generation for combustion of a single coal particle in quiescent, hot atmosphere. Because of the stationarity of the particle, spherico-symmetric governing equations were solved in this work. The influences of coal particle diameter and chemical composition and also those of the free stream temperature on the temporal evolution of the irreversibilities were further analysed in Ref. [35]. Baloyi et al. [36] examined the steady, exergetic behaviour of a small-scale wood-fired fluidised bed combustor. This study was primarily concerned with the effects of air fuel ratio upon the rate of entropy generation of an adiabatic burner. It was shown that there is an optimal value of air fuel ratio for which the entropy generation is minimal [36]. Most recently, Wang et al. [37] conducted a numerical simulation on the transient combustion of biomass particles in oxygenated, active atmospheres. These authors calculated the spatio-temporal evolution of the temperature and major chemical species during the devolatilisation, combustion and post-combustion stages [37]. An unsteady entropy generation theory was also developed on the basis of the earlier work of Pope et al. [33]. The numerical simulations of transient combustion of single biomass particle were subsequently used to construct a spatio-temporal model of entropy generation in the transient burning process [37]. To the best of authors' knowledge, as of now the work of Wang et al. [37] is the only study on unsteady entropy generation in oxy-combustion of a single solid particle. It is inferred from the preceding discussion that the chemical compositions of the particle is of high significance in the evaluation of entropy generation during the transient burning processes. More importantly, thermo-physical and convective characteristics of the oxidising atmosphere are central to the thermodynamic irreversibilities of single particle combustion. Yet, there is, currently, no systematic investigation of these factors upon thermodynamic irreversibilities of oxy-coal combustion. Addressing this shortcoming is the main objective of the present work.

\section{Methodology}

\subsection{Problem configuration and numerical scheme}


The numerical simulations were conducted to simulate the experimental works of Khatami and co-workers [10][11][12]. These studies were concerned with the combustion process of single coal particles in a drop-tube furnace under various gas atmospheres. The drop-tube furnace was $250 \mathrm{~mm}$ long with diameter in $70 \mathrm{~mm}$ with a constant wall temperature at $1400 \mathrm{~K}$. The temperature of gas flow was $1200 \mathrm{~K}$, and the velocity was $4.55 \mathrm{~cm} / \mathrm{s}$ under active conditions. The initial temperature of coal particles under quiescent and active conditions was $750 \mathrm{~K}$ and $1050 \mathrm{~K}$, respectively. The diameter of particles was $80 \mu \mathrm{m}$. The fuel properties of coal particles and the operational conditions are shown in Tables 1 and 2, respectively. A 2D axisymmetric domain (shown in Figure 1) was used in the current study to conduct the numerical simulations. The computational grid was generated using ICEM. The grid with 29925 cells was chosen after grid-independency studies with different grid densities varying from 18950 to 52680 cells. The numerical modelling was conducted using an Euler-Lagrange model. A standard weighted-sum-of-grey-gases model (WSGGM) was used to model turbulence in the reactor. Further, P-1 radiation (spherical harmonic method) [38], single kinetic rate de-volatilisation [39] and multiple-surface-reactions combustion model (e.g., char- $\mathrm{O}_{2}$, char- $\mathrm{CO}_{2}$, and char- $\mathrm{H}_{2} \mathrm{O}$ ) [40][41][42] were employed. SIMPLE algorithm was implemented for velocity-pressure coupling and simulations were run in ANSYS FLUENT [40]. Appendix A provides the details of the governing equations solved numerically. Further, a summary of the methodology employed for the calculation of unsteady entropy generation has been given in Appendix B.

\subsection{Coal combustion model}

Devolatilisation of the coal particle, volatiles (represented by $\mathrm{CH}_{\mathrm{X}} \mathrm{O}_{\mathrm{Y}}$ ) combustion, char (represented by $\mathrm{C}_{(\mathrm{s})}$ ) oxidation and other gas phase reactions [38] are represented in the combustion model. Upon releasing, the particle is heated by the hot surrounding gases and is subject to thermal radiation from the reactor walls. Consequently, the moisture content is first evaporated (drying process). This is followed by the rapid release of the volatiles (devolatilisation process).

In the current work, the release of volatiles is described by a single rate model. It is assumed that the rate of devolatilisation is of first-order and therefore depends on the amount of volatiles remaining in the particle and can be expressed by global kinetics [43]. The pertinent reaction and its rate constant are:

$$
\begin{aligned}
& R 1: \text { Coal } \rightarrow \alpha \text { Volatile }+(1-\alpha) \text { Char }, \\
& k=\operatorname{Aexp}\left(-E_{a} / R_{u} T\right) .
\end{aligned}
$$

Here the distribution coefficient of volatiles in coal $\alpha$ is given by proximate analysis of fuel. Due to the complexity of the reactions, the chemical kinetics of the species in the volatiles are not fully understood yet [44]. Thus, volatiles are often treated as a single species, which varies on the basis of the type of coal and comprising carbon, hydrogen and oxygen $\left(\mathrm{CH}_{\mathrm{X}} \mathrm{O}_{\mathrm{Y}}\right)$ in a ratio determined by the ultimate analysis of coal [45]. For the coal used in this study, the volatile gas species are represented as $\mathrm{CH}_{1.48} \mathrm{O}_{0.43}$ [46]. It is further assumed that the char formed during the devolatilisation process is consumed entirely by heterogeneous reactions and that there is no ash. The char combustion generates carbon monoxide $(\mathrm{CO})$ and carbon dioxide $\left(\mathrm{CO}_{2}\right)$. The following heterogeneous reactions are considered here [40][41][42], which also include the steam reforming of char.

$$
\begin{aligned}
& R 2: C_{(s)}+\mathrm{O}_{2} \rightarrow \mathrm{CO}_{2}, \\
& R 3: C_{(s)}+0.5 \mathrm{O}_{2} \rightarrow \mathrm{CO}, \\
& R 4: C_{(s)}+\mathrm{CO}_{2} \rightarrow 2 \mathrm{CO}, \\
& R 5: C_{(s)}+\mathrm{H}_{2} \mathrm{O} \rightarrow \mathrm{H}_{2}+\mathrm{CO} .
\end{aligned}
$$


The reaction rate $K\left(\mathrm{kmol} / \mathrm{m}^{3} \mathrm{~s}\right)$ is defined as

$$
K=k_{a} C_{c(s)} C_{r g},
$$

and the reaction rate constant evaluated by the Arrhenius type relation is expressed as

$$
k=A T^{b} \exp \left(-E_{a} / R_{u} T\right)
$$

The homogeneous reaction of the volatiles is given by

$$
\text { R6: } \mathrm{CH}_{\mathrm{X}} \mathrm{O}_{Y}+\mathrm{mO}_{2} \rightarrow \mathrm{CO}_{2}+n \mathrm{H}_{2} \mathrm{O} \text {. }
$$

Equating the numbers of atoms of each element in the reactants to the number in the products gives:

$m=1+X / 4-Y / 2$

$n=X / 2$,

and the oxidation of carbon monoxide $(\mathrm{CO})$ [47] and hydrogen $\left(\mathrm{H}_{2}\right)$ [48] are described by the following homogeneous reactions,

$$
\begin{aligned}
& R 7: \mathrm{CO}+0.5 \mathrm{O}_{2} \rightarrow \mathrm{CO}_{2}, \\
& R 8: \mathrm{H}_{2}+0.5 \mathrm{O}_{2} \rightarrow \mathrm{H}_{2} \mathrm{O} .
\end{aligned}
$$

The reaction rates of these are given by

$$
K=A T^{b} \exp \left(-E_{a} / R_{u} T\right)\left[C_{R}\right]^{d}\left[C_{o x}\right]^{e} .
$$

In total, eight reactions are considered and a summary of the kinetics data implemented in the combustion modelling and the values of $b, d$ and $e$ in Eq. (13) are provided in Table 3.

\subsection{Validation}

Table 4 shows a comparison between the current numerical simulations and the experimental data reported by Khatamai et al. [10][11][12]. This includes comparing the ignition delay time, the total particle life time and also the maximum particle temperature for a number of cases with varying concentration of oxygen under both quiescent and active flows. In the experimental studies, the appearance and disappearance of the light emitted from the reactive particle was used to monitor the start and end points of the particle combustion through spectral measurement, and the temperature was obtained through signals post-processing [49][50]. While in the simulations, the ignition and extinction moments of the particle were deduced by the start and end points of char combustion reactions $(\mathrm{R} 2-\mathrm{R} 5)$. Further, the temperature of the particle was tracked under the discrete phase modelling (DPM).

The close agreement between the numerical results and the experimental data confirms the validity of the numerical simulations. It is further noted that, although not shown in here, combustion of single coal particles were also simulated in carbon dioxide containing atmospheres and compared favourably against the experimental data. Thus, in total 81 pairs of data points were used to ensure about the validity of the current numerical model.

\section{Results and discussion}

\subsection{Unsteady temperature and concentration fields}

Figure 2 depicts the spatio-temporal evolution of the gas temperate in a part of the reactor close to the particle. Two different oxygen concentrations have been shown for the cases with active and quiescent flow and the time intervals between the snapshots have been maintained constant. The investigated periods start from a moment after the ignition and extend for a period longer than the particle life time (see Table 4). As a result, the last parts of each subfigure correspond to non-reactive media. Figure 2 clearly shows that in the course of the burning 
process, a rise of the gas temperature occurs around the particle and also in a region shortly downstream of the dropping particle. As will be discussed later, the increase of temperature around the particle is due to the homogenous combustion of volatiles and heterogeneous combustion of char. However, the downstream hot gas is formed by the volatiles combustion. Figure 2 indicates that although changes in oxygen concentration alters duration of the burning process and gas temperature, the qualitative temperature field remains more and less independent of the mole fraction of oxygen.

Figures 3-6 show the spatio-temporal variations of the major chemical species during the combustion of single coal particle in active flow. For conciseness reasons, the equivalent figures for quiescent atmosphere are not shown here. Two different oxygen concentrations including an air like atmosphere (i.e. $21 \% \mathrm{O}_{2}$ and $79 \% \mathrm{~N}_{2}$ ) and pure oxygen $\left(100 \% \mathrm{O}_{2}\right)$ are shown in these figures. The temporal variation of $\mathrm{CO}$ distribution has been depicted in Fig.3. In both parts of this figure, the existence of CO is limited to a small region around the particle. This is due to the fact that the production of $\mathrm{CO}$ is through reactions R3-R5, which are all heterogeneous. Figure 3a indicates that the thickness of $\mathrm{CO}$ concentration boundary layer is larger to that in Fig. 3b. This can be explained by noting that shorter duration of the process in Fig. 3b, which corresponds to an oxygenated atmosphere, reduces the time available for the diffusion of carbon monoxide into the surrounding atmosphere. Since CO is an intermediate species and by the end of the combustion process it is totally consumed, the right most snapshots in Fig. $3 \mathrm{~b}$ show almost no carbon monoxide. The small amount of CO observed in the last snapshot of Fig. $3 \mathrm{a}$ is because of the slow kinetics of carbon monoxide oxidation and will eventually disappear due to the oxidation of $\mathrm{CO}$ and conversion to $\mathrm{CO}_{2}(\mathrm{R} 7)$.

Figure 4 shows the formation and transport of $\mathrm{CO}_{2}$ in air like and pure oxygen atmospheres. It is clear from Fig. 4a that, when burning in air like condition, a large amount of $\mathrm{CO}_{2}$ is generated shortly after the particle ignition. Combustion of volatiles described by reaction R6, combustion of $\mathrm{CO}$ (R7) and also heterogeneous char combustion (R2) contribute with the generation of carbon dioxide. Amongst these, oxidation of volatiles happens immediately after the ignition and progresses very fast. As a result, there is a large amount of $\mathrm{CO}_{2}$ production in the early stages of the burning process (see the left most snapshot in Fig. 4a). As time elapses, the $\mathrm{CO}_{2} \mathrm{Cloud}$ forms by combustion of volatiles diffuses into the atmosphere, while being advected downstream by the motion of the atmosphere. Since the products of the homogeneous combustion of volatiles are at high temperature (see Fig. 2), the buoyancy force slows down the downstream motion of the $\mathrm{CO}_{2}$ cloud. Hence, in Fig. 4a, there appears to be two distinctive regions with high $\mathrm{CO}_{2}$ concentration. This is less pronounced under combustion in pure oxygen shown in Fig. 4b in which the short duration of combustion does not allow for the buoyancy force to develop two regions of high $\mathrm{CO}_{2}$ concentration.

Unsteady production and the subsequent consumption of hydrogen during the combustion process is depicted in Fig. 5. Hydrogen is produced by water gas reaction (R5) and is then consumed by hydrogen oxidation reaction (R8). The second reaction supports the first one through production of water vapour. Nonetheless, the hydrogen is totally consumed by the end of the particle life time. Figure 5 indicates that the oxygen concentration has a strong effect upon $\mathrm{H}_{2}$ concentration boundary layer. Combustion in air like atmosphere (Fig. 5a) generally results in a thicker boundary layer compared to that in pure oxygen atmosphere (Fig. 5b). This is due to the wide diffusion of hydrogen into the surrounding atmosphere in air like condition, which does not happen in pure oxygen condition. Given that the binary diffusion coefficient of hydrogen in $21 \% \mathrm{O}_{2}$ and $79 \% \mathrm{~N}_{2}$ environment is not very 
different to that in oxygen, the disparity can be attributed to the longer process time of combustion in $21 \% \mathrm{O}_{2}$ and $79 \% \mathrm{~N}_{2}$ environment. This is also clear by comparing the distance that hydrogen plume travels in each case.

Figure 6 illustrates the temporal evolution of water vapour during the burning process. Here a behaviour similar to that of carbon dioxide (Fig. 4) is observed. A large amount of $\mathrm{H}_{2} \mathrm{O}$ is produced after the ignition through oxidation of volatiles (R6). Water vapour is also produced by the oxidation of hydrogen (R8), which in turn is produced in a heterogeneous reaction of steam gasification of coal (R5). As a result, there are two local sources of $\mathrm{H}_{2} \mathrm{O}$. One is located within the flame produced by the combustion of volatiles and the other is around the burning particle. The progressive diffusion of the $\mathrm{H}_{2} \mathrm{O}$ cloud into the surrounding atmosphere is apparent in Figs. 6a and 6b. Similar to that explained with regard to $\mathrm{CO}_{2}$ in Fig. 4, the buoyancy force hinders the downstream motion of $\mathrm{H}_{2} \mathrm{O}$ cloud and thus as time goes on there are two distinctive regions in the reactor with significant $\mathrm{H}_{2} \mathrm{O}$ concentration.

Consumption of oxygen is an important parameter governing the combustion process and thus the evolution of oxygen boundary layer is of high significance. Figure 7 shows the radial distribution of oxygen mass fraction at different times during the burning process. In each subfigure, the horizontal axis represents the radial distance measured from the surface of the particle. Both active and quiescent flows with varying concentration of oxygen have been investigated in this figure. Reduction of oxygen concentration near the particle is evident in all subfigures. At early times this is due to the homogenous oxidation of volatiles (R6), whereas during the char combustion the heterogeneous reactions $\mathrm{R} 2$ and $\mathrm{R} 3$ as well as the homogeneous oxidation of $\mathrm{CO}(\mathrm{R} 7)$ and $\mathrm{H}_{2}$ (R8) consume oxygen. Figure 7 provides a clear indication about the thickness of the concentration boundary layer formed by the oxygen deficit. This is where, for a given instance of time, the oxygen concentration profile asymptotically approaches that of the longest duration of time $(29 \mathrm{~ms}$ for the active flow and $50 \mathrm{~ms}$ for quiescent flow). Figures 7 a to $7 \mathrm{~d}$ show that, under active flow, increasing the mole fraction of oxygen results in the growth of the thickness of the concentration boundary layer. Further, the amount of oxygen deficit within the boundary layer increases significantly as the mole fraction of the oxygen increases. It is important to note that as the initial mass of the particle has been maintained constant throughout all experiments and simulations, the total amount of oxygen consumed in the course of the burning process is fixed. The faster combustion in oxygenated atmospheres causes consumption of the required oxygen in a short time, rendering smaller concentrations of oxygen in the vicinity of the coal particle. This behaviour is equally observable in cases under active flow (Figs. 7a-d) and also for those under the quiescent flow (Figs. 7e-h).

Figure 8 shows the history of mole fraction of the species for two different chemical atmospheres and with and without advection in the surrounding atmosphere. An air like atmosphere and pure oxygen have been analysed in this figure. In Figs. 8a-d, the release of volatiles immediately after dropping the particle (at $t=0)$ is evident. The mole fraction of volatiles increases at the beginning of the devolatilisation process till it reaches a maximum value at the moment of ignition. It then drops quickly, indicating the fast combustion rate of the volatiles. It should be clarified that as Fig. 8 and Table 4 show, ignition happens quicker in the active flow compared to the quiescent flow. This is due to the difference in the initial temperatures of the coal particle in these two cases (see Table 2). Ignition and oxidation of volatiles results in very fast production of $\mathrm{CO}_{2}$ and $\mathrm{H}_{2} \mathrm{O}$ through the homogenous reaction R6. By termination of the combustion of volatiles, the rate of $\mathrm{CO}_{2}$ and $\mathrm{H}_{2} \mathrm{O}$ production decreases significantly. At the char combustion phase, these species are predominantly generated by reactions R2 and R8. Further, production of a relatively small amount of carbon monoxide and hydrogen by reactions R3, R4 and R5 
can be readily seen in Fig. 8. $\mathrm{CO}$ and $\mathrm{H}_{2}$ are eventually converted to carbon dioxide and water vapour through reactions R7 and R8. According to Fig. 8, the chemical and advection characteristics of the atmosphere have strong effects upon the formation and consumption of the species. A comparison between Figs. $8 \mathrm{a}$ and $8 \mathrm{~b}$ shows that by replacing air with pure oxygen, the concentrations of $\mathrm{CO}$ and $\mathrm{H}_{2}$ have majorly dropped. The same trend can be seen for the cases under quiescent flow shown in Figs. 8c and 8d. This is because of the fast progress of reactions $\mathrm{R} 7$ and $\mathrm{R} 8$ in oxygen, which deplete $\mathrm{CO}$ and $\mathrm{H}_{2}$ quickly and hence maintain their concentrations at low levels.

\subsection{Unsteady thermodynamic irreversibilities}

Figures 9-12 illustrate the spatio-temporal evolution of entropy generation within a moving window travelling with the particle. Contours of the entropy generation by thermal and mass transfer, and chemical irreversibilities (as identified in Appendix B) have been plotted for three different moments of time. An air like atmosphere under quiescent flow has been investigated in Fig. 9. This figure shows that shortly after the ignition $(t=18 \mathrm{~ms})$, there exists a large region around the particle with strong chemical irreversibility. The highest rate of chemical entropy generation happens in the vicinity of the particle, while chemical irreversibility remains strong in a region around the particle wherein the volatiles are oxidised. Figure 9 also indicates that thermal and mass transfer irreversibilities are limited to the areas close to the particle and their strengths are comparable to that of chemical irreversibility. In the second snapshot of this figure, at $t=30 \mathrm{~ms}$ the strength of the chemical irreversibility has decreased, although it still affects a relatively large area of the domain. This is due to the fact that at this stage the volatile combustion is complete and the homogenous reactions are limited to the oxidation of carbon monoxide and hydrogen (see Fig. 8c). The next snapshot has been produced at $t=100 \mathrm{~ms}$, which corresponds to a post combustion moment. As expected, the chemical irreversibility at this moment is almost zero. The mass transfer irreversibility has dropped to very low values. However, the thermal irreversibility remains at a noticeable value. This is because of the diffusion of the hot gases into the surrounding medium, which takes a longer time than completion of the combustion process.

Figure 10 depicts the same sequence, shown in Fig. 9, for the combustion of the coal particle in quiescent, pure oxygen atmosphere. At the first moment $(t=11.5 \mathrm{~ms})$, all the sources of irreversibility have values much greater than those in air combustion shown in Fig. 9. In particular, the thermal entropy has become stronger by two orders of magnitude. Further, in contrast to that in Fig. 9, the chemical entropy generation remains equally strong for the second snapshot at $t=18 \mathrm{~ms}$. It can be verified in Fig. $8 \mathrm{~d}$ that at this time the only homogenous reactions are combustion of $\mathrm{H}_{2}$ and $\mathrm{CO}$. However, it seems that the fast reactions in pure oxygen maintain the high level of chemical irreversibility even after the termination of volatiles combustion. Figure $10 \mathrm{~g}$ shows that, once again, thermal entropy generation is the only form of irreversibilities at post combustion stage.

Figures 11 and 12 illustrate the spatio-temporal evolution of the entropy generation sources in two active flow cases. In these two figures, the first snapshots are produced at pre-ignition moment $(t=3 \mathrm{~ms})$, which expectedly includes no chemical irreversibility but considerable mass transfer irreversibility (see Figs. 11b and 12b). Further, there is noticeable thermal entropy generation in Figs. 11a and 12a. This is due to the endothermicity of the process of volatiles release, which sets a temperature gradient around the devolatising coal particle. The second snapshot at $t=7 \mathrm{~ms}$ (parts $\mathrm{d}$, e and $\mathrm{f}$ of Figs. 11 and 12) captures a moment during combustion, in which all sources of irreversibility are strong. Figures $12 \mathrm{~d}, 12 \mathrm{e}$ and $12 \mathrm{f}$ show that at $\mathrm{t}=30 \mathrm{~ms}$ and for pure oxygen, all types of entropy 
generation occur in two distinctive regions, one around the particle and the other in the downstream flow. The former is because of the char combustion reactions (R2- R5) and the subsequent homogenous reactions (R7 and R8). The latter, however, is caused by the combustion of volatiles (R6). Figures $11 \mathrm{~g}, 11 \mathrm{~h}$ and $11 \mathrm{i}$ indicate that towards the end of the particle life time $(t=40 \mathrm{~ms})$, the thermal and mass transfer entropy generations are highly suppressed. However, in these figures the chemical irreversibility is still quite strong.

Figure 13 shows the history of entropy generation by different sources of irreversibility and for different velocities and compositions of the atmosphere. To produce this figure, Eqs. B13a, b and c have been integrated over the effective area and this was repeated for the first 100ms seconds after the release of the coal particle. Figures 13a and $13 \mathrm{~b}$ correspond to a moderately oxygenated case $\left(37 \% \mathrm{O}_{2} \& 63 \% \mathrm{~N}_{2}\right)$ under active flow. This figure shows that upon the release of the particle and up to the moment of ignition, mass transfer irreversibility is the strongest source of entropy generation. Within this period, the thermal entropy generation is rather weak and there is no chemical irreversibility. The diffusion of volatiles into the surrounding environment and also the supply of heat to the endothermic devolatilisation process are the two irreversible phenomena occurring in this period. Ignition of the volatile gases results in a very sharp increase of the chemical entropy and thermal entropy generation. However, this trend is reversed after a short period and the chemical entropy generation drops down to very small values by the end of homogenous combustion phase. In general, the same qualitative behaviour is observed in the thermal entropy. However, as shown in Fig. 13b the thermal entropy increases towards the end of the particle life time and keeps growing after the completion of the burning process. This is because of the diffusion of heat of combustion into the surrounding medium and is a major contributor to the thermal entropy generated during the transient combustion process. By increasing the concentration of oxygen in Figs. 13c and 13d an interesting behaviour becomes apparent. Here, the rates of decrease in the chemical and thermal entropy generation after the combustion of volatiles are much less than those in Figs. 13a and 13b. Hence, the chemical and entropy generations remain large for the entire course of particle burning. This is due to the strengthening of reactions R2, R3 and also R7 in the highly oxygenated atmosphere, which intensify the rate chemical reactions and heat release of char combustion.

Under quiescent flow and in an atmosphere similar to air, Figs. $13 \mathrm{e}$ and $13 \mathrm{f}$ show that the mass transfer irreversibility in the pre-ignition period is more significant than the thermal irreversibility during the homogenous combustion. Similar to that discussed earlier, the thermal irreversibility continues to grow within the char combustion and post-combustion periods and ultimately becomes much more significant than the mass transfer entropy generation. Major intensification of chemical entropy generation in pure oxygen atmosphere is evident in Figs. $13 \mathrm{~g}$ and $13 \mathrm{~h}$. Also these figures clearly show that during the combustion volatiles, thermal entropy generation is much larger than that of mass transfer. As a general trend in Figs. 13a-h, all the time traces of mass transfer irreversibility feature two peaks. First, during the devolatilisation process, which results in the production of gas-phase volatiles, and the second peak after the ignition and during the combustion of volatiles and char.

The total amount of entropy generated within the system is calculated in Eq. B16 and by time averaging the spatially integrated entropy generation discussed with regards to Fig. 13. Here, the time averaging was conducted for an interval of $200 \mathrm{~ms}$. Although not shown, this period was enough for the thermal gradients in the reactor to mostly smear out and thus the process of entropy generation to nearly come to the end. Figure 14 shows the total entropy generation for different chemical compositions of the atmosphere and also for the active and quiescent flows. Also shown in this figure is the sum of the three sources of entropy, here referred to as global entropy 
generation within the system. A close examination of the graphs in Fig. 14 reveals a few points as follows. First, in keeping with the findings of the previous studies on steady gaseous combustion [19] and transient multiphase combustion [19][33][37], mass transfer irreversibility appears to be small in comparison with that of heat transfer and chemical reactions. Second, oxygenation of the atmosphere generally results in a significant increase in the global entropy generation in comparison with combustion in air. A step change is particularly visible in the chemical entropy generation. This result is of high practical significance, as it indicates that slight and moderate oxygenation of the combustion atmosphere can majorly boost the level of entropy generation and hence that of exergy destruction. However, once the mole fraction of oxygen reaches around $40 \%$ (37\% for active flow), any further oxygenation causes only slight increases in the entropy generation. Third, under quiescent flow there appears to be a regular pattern of increasing entropy generation by increasing the concentration of oxygen. However, this pattern is less clear in active flow cases. Fourth, although the global entropy generation for the active and quiescent flows are nearly the same, the thermal entropy generation in quiescent flow is noticeably smaller than that of the active flows cases. The reason for this behaviour is not immediately obvious and is anticipated to be due to the modification of heat transfer by altering the flow velocity.

\section{Conclusions}

Transient combustion of single coal particles in $\mathrm{O}_{2} / \mathrm{N}_{2}$ atmospheres with varying chemical compositions and for active and quiescent flows was investigated numerically. The process of devolatilisation, combustion of volatiles and char and also post-combustion diffusion of heat and mass into the atmosphere were analysed in detail. The results were validated against the existing experimental data. The spatio-temporal evolution of the temperature and species concentrations fields, as well as that of unsteady entropy generations were presented and the total entropy generations were calculated. The main findings of this work can be summarised as follows.

- For all investigated cases, the highest rate of chemical reactions occurs during combustion of volatiles. The initiation of char combustion is always associated with slowing down the reactions.

- Due to the high rate of combustion during volatile combustion, transport of mass is most active during this period. However, gas phase mass transfer is significantly suppressed at the char combustion stage.

- Generation of entropy in the devolatilisation period is dominated by the irreversibility of mass transfer. However, a very sharp increase in chemical entropy generation is observed immediately after the ignition. For the oxygenated cases the thermal entropy also grows substantially within the homogenous combustion phase.

- Similar to that reported in steady homogeneous combustion processes, the mass transfer irreversibility is found insignificant before the irreversibility of heat transfer and chemical reactions. The latter appears to be the largest contributor with the global entropy generation.

- While chemical entropy generation comes to an end by the termination of the particle life time, the thermal entropy counties to be generated for a relatively long time ( $200 \mathrm{~ms})$. This is due to the diffusion of heat of combustion into the surrounding atmosphere.

- Oxygenation of the atmosphere results in an increase in the global entropy generation. This increase is quite significant when moderately oxygenated atmospheres (with mole fraction of oxygen less than 40\%) are compared with air. However, addition of further oxygen results in minor increases in the total entropy 
generation by the chemical and thermal mechanisms and thus alters the global entropy generation of the process insignificantly. 


\section{Appendix A: Governing equations}

Throughout the current investigation it is assumed that the coal particles are spherical with nominal diameter of $80 \mu \mathrm{m}[10][11][12]$. Further, the gaseous atmosphere is treated as an ideal-gas mixture and calculation of all relevant thermo-physical properties is on this basis. The governing equations solved simultaneously by the computational model are the followings. It is noted that the selection of an axisymmetric, cylindrical configuration is consistent with the experimental setup [10][11] and also the previous numerical investigations on similar problems [37].

The conservation of mass:

$$
\frac{\partial \rho}{\partial t}+\frac{\partial}{\partial x}\left(\rho u_{x}\right)+\frac{\partial}{\partial r}\left(\rho u_{r}\right)+\frac{\rho u_{r}}{r}=0
$$

The conservations of momentum in the axial and radial directions are written as,

$$
\begin{aligned}
& \frac{\partial\left(\rho u_{x}\right)}{\partial t}+\frac{1}{r} \frac{\partial}{\partial x}\left(r \rho u_{x} u_{r}\right)+\frac{1}{r} \frac{\partial}{\partial r}\left(r \rho u_{x} u_{r}\right) \\
& =-\frac{\partial p}{\partial x}+\frac{1}{r} \frac{\partial}{\partial x}\left[r \mu_{o}\left(2 \frac{\partial u_{x}}{\partial x}-\frac{2}{3}(\nabla \cdot \vec{u})\right)\right]+\frac{1}{r} \frac{\partial}{\partial r}\left[r \mu_{o}\left(\frac{\partial u_{x}}{\partial r}+\frac{\partial u_{r}}{\partial x}\right)\right]+\rho g_{x}, \\
& \frac{\partial\left(\rho u_{r}\right)}{\partial t}+\frac{1}{r} \frac{\partial}{\partial x}\left(r \rho u_{x} u_{r}\right)+\frac{1}{r} \frac{\partial}{\partial r}\left(r \rho u_{r} u_{r}\right) \\
& =-\frac{\partial p}{\partial r}+\frac{1}{r} \frac{\partial}{\partial x}\left[r \mu_{o}\left(\frac{\partial u_{x}}{\partial r}+\frac{\partial u_{r}}{\partial x}\right)\right]+\frac{1}{r} \frac{\partial}{\partial r}\left[r \mu_{o}\left(2 \frac{\partial u_{r}}{\partial r}-\frac{2}{3}(\nabla \cdot \vec{u})\right)\right] \\
& \quad-2 \mu_{o} \frac{u_{r}}{r^{2}}+\frac{2}{3} \frac{\mu_{o}}{r}(\nabla \cdot \vec{u}) .
\end{aligned}
$$

Transport of energy for the reactive flow is expressed by,

$$
\frac{\partial\left(\rho h^{\prime}\right)}{\partial t}+\frac{\partial\left(\rho h^{\prime} u_{r}\right)}{\partial r}+\frac{\partial\left(\rho h^{\prime} u_{x}\right)}{\partial x}=\frac{\partial p}{\partial t}-\frac{\partial q_{j}}{\partial(x, r)}+Q_{r}
$$

and the conservation of chemical species takes the form of

$$
\frac{\partial\left(\rho Y_{i}\right)}{\partial t}+\frac{\partial\left(\rho Y_{i} u_{r}\right)}{\partial r}+\frac{\partial\left(\rho Y_{i} u_{x}\right)}{\partial x}=\frac{\partial\left(J_{i, j}\right)}{\partial(x, r)}+R_{i}
$$

The ideal gas law for the multicomponent gaseous atmosphere is written as

$$
p=\rho R_{u} T \sum_{i}^{N} \frac{Y_{i}}{M_{i}}
$$

The transient motion of the coal particle and an estimation of aerodynamic forces were also included in the computational model. These were modelled by considering the gravitational and aerodynamic lift forces described by the following equations [40].

$$
\begin{aligned}
& m_{p} \frac{d u_{p}}{d t}=F_{d}\left(u_{g}-u_{p}\right)+g_{x}\left(\rho_{p}-\rho\right) \\
& F_{d}=\frac{3 \mu_{m}}{\rho_{p} d_{p}^{2}} \frac{C_{D} R e_{p}}{4} \\
& R e_{p}=\frac{\rho d_{p}\left|u_{p}-u_{g}\right|}{\mu_{g}} \\
& C_{D}=a_{1}+\frac{a_{2}}{R e_{p}}+\frac{a_{3}}{R e_{p}^{2}}
\end{aligned}
$$


Further, the transport of thermal energy for the particle is given by the following equation. This equation considers convection and radiation heat transfer and takes into account the phase change and mass loss of the particle [43][46].

$$
m_{p} c_{p, p} \frac{d T_{p}}{d t}=\pi d_{p} \lambda N u\left(T_{g}-T_{p}\right)+A_{p} \varepsilon_{p} s_{b}\left(\theta_{R}^{4}-T_{p}^{4}\right)+\frac{d m_{p}}{d t} h_{f g}-f_{h} \sum_{i} \frac{d m_{p}}{d t} H_{r e a c_{c r}}
$$

in which the Nusselt number is given by the following equation.

$$
N u=2.0+0.6 \cdot R e_{p}^{1 / 2} \cdot\left(c_{p} \mu_{g} / \lambda\right)^{1 / 3} .
$$

In Eq. A7a the first term on the left-hand side represents the rate of change in the sensible enthalpy of the particle. Also, the first and second terms on the right-hand side represent the heat transfer from the particle through the mechanisms of convection and radiation. The third term is the temporal rate of change in the latent heat and includes the depletion of particle mass due to oxidation. The last term on the right-hand side shows the fraction of the enthalpy of heterogeneous reactions, which is absorbed by the particle.

\section{Appendix B. Unsteady entropy generation}

The unsteady entropy generation model is on the basis of the governing equations and Gibbs equation [51]. The main steps of this derivation are summarised in the followings. The Gibbs equation for a multi-component gaseous mixture is written as

$$
T d s=d u+p d\left(\frac{1}{\rho}\right)-\sum_{i} \mu_{c, i} d Y_{i}
$$

An algebraic manipulation of Eq. (14) reveals,

$$
T \frac{\partial s}{\partial t}=\frac{\partial u}{\partial t}-\frac{p}{\rho^{2}} \frac{\partial \rho}{\partial t}-\sum_{i} \overline{\mu_{c, l}} \frac{\partial Y_{i}}{\partial t}
$$

in which $\mu_{c, i}=\overline{\mu_{c, l}} / M_{i}$ is the specific chemical potential.

Substituting the governing equations (A1) -(A3) into Gibbs equation and multiplying the result by $\rho / T$ yields

$$
\rho \frac{\partial s}{\partial t}=-\frac{1}{T} \nabla \cdot \vec{q}+\frac{\Phi}{T}+\frac{\rho}{T} \sum_{i} Y_{i} \vec{f}_{l} \cdot \vec{V}_{l}-\frac{1}{T} \sum_{i} \mu_{c, i}\left[\omega_{i}-\nabla \cdot\left(\rho Y_{i} \vec{V}_{l}\right)\right],
$$

which can be then reformulated as

$$
\begin{aligned}
\rho \frac{\partial s}{\partial t}=-\nabla \cdot\left[\left(\frac{\vec{q}}{T}\right)\right. & \left.-\frac{1}{T} \sum_{i} \mu_{c, i} \rho Y_{i} \vec{V}_{l}\right]-\frac{\vec{q}}{T^{2}} \cdot \nabla T+\frac{\Phi}{T}+\frac{\rho}{T} \sum_{i} Y_{i} \vec{f}_{l} \cdot \vec{V}_{l} \\
& -\frac{1}{T} \sum_{i} \mu_{c, i} \omega_{i}+\frac{1}{T^{2}} \sum_{i} \mu_{c, i} \rho Y_{i} \vec{V}_{l} \cdot \nabla T-\frac{1}{T} \sum_{i} \rho Y_{i} \vec{V}_{l} \cdot \nabla\left(\mu_{c, i}\right) .
\end{aligned}
$$

Considering the equation of change for entropy in Ref. [52], the following equations can be obtained:

$$
\vec{s}=\left(\frac{\vec{q}}{T}\right)-\frac{1}{T} \sum_{i} \mu_{c, i} \rho Y_{i} \vec{V}_{l}
$$

and

$$
\sigma=-\frac{\vec{q}}{T^{2}} \cdot \nabla T+\frac{\Phi}{T}+\frac{\rho}{T} \sum_{i} Y_{i} \vec{f}_{l} \cdot \vec{V}_{l}-\frac{1}{T} \sum_{i} \mu_{c, i} \omega_{i}+\frac{1}{T^{2}} \sum_{i}\left(\mu_{c, i} \rho Y_{i} \vec{V}_{l}\right) \cdot \nabla T-\frac{1}{T} \sum_{i} \rho Y_{i} \vec{V}_{l} \cdot \nabla\left(\mu_{c, i}\right) .
$$

Equation (B6) can be converted into a form similar to that given by Carrington and Sun [53]: 


$$
\sigma=-\frac{\vec{q}}{T^{2}} \cdot \nabla T+\frac{\Phi}{T}+\frac{1}{T} \sum_{i} \rho Y_{i} \vec{V}_{l} \cdot\left(\vec{f}_{l}+\frac{\mu_{c, i}}{T} \nabla T-\nabla \mu_{c, i}\right)-\frac{1}{T} \sum_{i} \mu_{c, i} \omega_{i} .
$$

At any given point, the total heat flux $\vec{q}$ can be defined in the following form

$$
\vec{q}=-\lambda \cdot \nabla T+\rho \sum Y_{i} \overrightarrow{V_{l}} h_{i},
$$

It is then assumed that the viscous dissipation contribution with the entropy generation is negligible, verified in large number of previous studies [17]. This renders

$$
\begin{aligned}
& \mu_{c, i}=h_{i}-T s_{i}, \\
& s_{i}=s_{i}^{0}+\int_{T^{0}}^{T} \frac{c_{p, i}}{T} d T-\frac{R_{u}}{M_{i}} \ln \left(\frac{p}{p^{0}}\right)-\frac{R_{u}}{M_{i}} \ln X_{i}, \\
& \nabla X_{i}=\sum_{\substack{j=1 \\
j \neq i}}^{N}\left(\frac{X_{i} X_{j}}{D_{i j}}\right)\left(\overrightarrow{V_{J}}-\overrightarrow{V_{l}}\right)+\sum_{\substack{j=1 \\
j \neq i}}^{N}\left(\frac{X_{i} X_{j}}{D_{i j}}\right)\left(\frac{D_{T, j}}{\rho_{j}}-\frac{D_{T, i}}{\rho_{i}}\right)\left(\frac{\nabla T}{T}\right) .
\end{aligned}
$$

Combining these equations yields the entropy generation of the process as

$$
\sigma=\frac{\lambda}{T^{2}}(\nabla T)^{2}+\frac{\rho R_{u} D_{i m}}{\bar{M}} \frac{1}{X_{i}}\left(\nabla X_{i}\right)^{2}-\frac{1}{T} \sum_{i} \mu_{c, i} \omega_{i}
$$

The terms on the right-hand side of Eq. (33) represent the rate of entropy generation duo to heat transfer $\left(E_{h}\right)$, mass transfer $\left(E_{m}\right)$, and chemical reactions $\left(E_{r}\right)$, respectively.

$$
\begin{aligned}
& E_{h}=\frac{\lambda}{T^{2}}(\nabla T)^{2}, \\
& E_{m}=\frac{\rho R_{u} D_{i m}}{\bar{M}} \frac{1}{X_{i}}\left(\nabla X_{i}\right)^{2}, \\
& E_{r}=-\frac{1}{T} \sum_{i} \mu_{c, i} \omega_{i} .
\end{aligned}
$$

Eq. (B14) represents the rate of entropy generation per unit volume and hence the instantaneous entropy generation rate in the entire system can be found integrating that over a volume:

$$
E=\int \sigma d s_{E}
$$

Finally, time averaging of Eq. (B16) reveals the entropy generation over the entire course of the burning process. That is

$$
E^{\prime}=\frac{1}{t_{t}} \int_{0}^{t_{t}} E d t .
$$

\section{Acknowledgment}

Linwei Wang acknowledges the financial support of Chinese Scholarship Council and the University of Glasgow through a PhD scholarship. 


\section{References}

[1] Dudley B. BP statistical review of world energy June 2012, 2012, London, UK.

[2] Chen L, Yong SZ, Ghoniem AF. Oxy-fuel combustion of pulverized coal: Characterization, fundamentals, stabilization and CFD modeling. Progress in energy and combustion science, 2012, 38(2): 156-214.

[3] Edge P, Gharebaghi M, Irons R, Porter R, Porter RTJ, Pourkashanian M, Smith D, Stephenson P, Williams A. Combustion modelling opportunities and challenges for oxy-coal carbon capture technology. Chemical Engineering Research and Design, 2011, 89(9): 1470-1493.

[4] Li L, Duan LB, Zeng D, Lu DY, Bu CS, Zhao CS. Ignition and volatile combustion behaviors of a single lignite particle in a fluidized bed under $\mathrm{O}_{2} / \mathrm{H}_{2} \mathrm{O}$ conditions. Proceedings of the Combustion Institute, 2018, https://doi.org/10.1016/j.proci.2018.05.038.

[5] Kaushik SC, Reddy VS, Tyagi SK. Energy and exergy analyses of thermal power plants: A review. Renewable and Sustainable Energy Reviews. 2011, 15(4): 1857-1872.

[6] Gürtürk M, Oztop HF. Exergy analysis of a circulating fluidized bed boiler cogeneration power plant. Energy Conversion and Management, 2016, 120: 346-357.

[7] Abdelmotalib HM, Youssef MAM, Hassan AA, Youn SB, Im IT. Heat transfer process in gas-solid fluidized bed combustors: a review. International Journal of Heat and Mass Transfer, 2015, 89: 567-575.

[8] Bu CS, Liu DY, Chen XP, Pallarès D, Gómez-Barea A. Ignition behavior of single coal particle in a fluidized bed under $\mathrm{O}_{2} / \mathrm{CO}_{2}$ and $\mathrm{O}_{2} / \mathrm{N}_{2}$ atmospheres: A combination of visual image and particle temperature. Applied Energy, 2014, 115: 301-308.

[9] Hookyung L, Choi S. An observation of combustion behavior of a single coal particle entrained into hot gas flow. Combustion and Flame, 2015, 162(6): 2610-2620.

[10] Khatami R, Stivers C, Joshi K, Levendis YA, Sarofim AF. Combustion behaviour of single particles from three different coal ranks and from sugar cane bagasse in $\mathrm{O}_{2} / \mathrm{N}_{2}$ and $\mathrm{O}_{2} / \mathrm{CO}_{2}$ atmospheres. Combustion and Flame, 2012, 159(3): 1253-1271.

[11] Khatami R, Stivers C, Levendis YA. Ignition characteristics of single coal particles from three different ranks in $\mathrm{O}_{2} / \mathrm{N}_{2}$ and $\mathrm{O}_{2} / \mathrm{CO}_{2}$ atmospheres. Combustion and Flame, 2012, 159(12): 3554-3568.

[12] Maffei T, Khatami R, Pierucci S, Faravelli T, Ranzi E, Levendis YA. Experimental and modelling study of single coal particle combustion in $\mathrm{O}_{2} / \mathrm{N}_{2}$ and Oxy-fuel $\left(\mathrm{O}_{2} / \mathrm{CO}_{2}\right)$ atmospheres. Combustion and Flame, 2013, 160(11): 2559-2573.

[13] Moon C, Sung Y, Ahn S, Kim T, Choi G, Kim D. Thermochemical and combustion behaviors of coals of different ranks and their blends for pulverized-coal combustion. Applied Thermal Engineering, 2013, 54: 111-119.

[14] Brix J, Navascués LG, Nielsen JB, Bonnek PL, Larsen HE, Clausen S, Glarborg P, Jensen AD. Oxy-fuel combustion of millimeter-sized coal char: Particle temperatures and NO formation. Fuel, 2013, 106: 72-78.

[15]Zhou H, Huang Y, Mo GY, Liao ZY, Cen KF. Experimental investigations of the conversion of fuel-N, volatile- $\mathrm{N}$ and char- $\mathrm{N}$ to $\mathrm{NO}_{\mathrm{x}}$ and $\mathrm{N}_{2} \mathrm{O}$ during single coal particle fluidized bed combustion. Journal of the Energy Institute, 2017, 90(1): 62-72.

[16] Shen J, Liu JX, Zhang H, Jiang XM. $\mathrm{NO}_{\mathrm{x}}$ emission characteristics of superfine pulverized anthracite coal in air-staged combustion. Energy Conversion and Management, 2013, 74: 454-461. 
[17] Köser J, Becker LG, Vorobiev N, Schiemann M, Scherer V, Böhm B, Dreizler A. Characterization of single coal particle combustion within oxygen-enriched environments using high-speed OH-PLIF. Applied Physics B, 2015, 121(4): 459-464.

[18] Köser J, Becker LG, Goßmann AK, Böhm B, Dreizler A. Investigation of ignition and volatile combustion of single coal particles within oxygen-enriched atmospheres using high-speed OH-PLIF. Proceedings of the Combustion Institute, 2017, 36(2): 2103-2111.

[19] Som SK, Datta A. Thermodynamic irreversibilities and exergy balance in combustion processes. Progress in Energy and Combustion Science, 2008, 34(3): 351-376.

[20] Torabi M, Zhang KL, Karimi N, Peterson GP. Entropy generation in thermal systems with solid structures-a concise review. International Journal of Heat and Mass Transfer, 2016, 97: 917-931.

[21] Torabi M, Karimi N, Peterson GP. Challenges and progress on modeling of entropy generation in porous media: A review. International Journal of Heat and Mass Transfer, 2017, 114: 31-46.

[22] Chakraborty S, Aviral R, Sandeep PS, Prabal T. Heat transfer and discrete phase modelling of coal combustion in a pusher type reheating furnace. Applied Thermal Engineering, 2017, 116: 66-78.

[23] Gaikwad P, Kulkarni H, Sreedhara S. Simplified numerical modelling of oxy-fuel combustion of pulverized coal in a swirl burner. Applied Thermal Engineering, 2017, 124: 734-745.

[24]Zhou Z, Xue Q, Li C, Wang G, She X, Wang J. Coal flow and combustion characteristics under oxygen enrichment way of oxygen-coal double lance. Applied Thermal Engineering, 2017, 123: 1096-1105.

[25] Wsng M, Liao B, Liu Y, Wang S, Qing S, Zhang A. Numerical simulation of oxy-coal combustion in a rotary cement kiln. Applied Thermal Engineering, 2016, 103: 491-500.

[26] Johansson R, Leckner B, Andersson K, Johnsson F. Influence of particle and gas radiation in oxy-fuel combustion. International Journal of Heat and Mass Transfer, 2013, 65: 143-152.

[27] Chabane A, Truffin K, Nicolle A, Nicoud F, Cabrit O, Angelberger C. Direct Numerical Simulation of combustion near a carbonaceous surface in a quiescent flow. International Journal of Heat and Mass Transfer, 2015, 84: 130-148.

[28] Tufano GL, Stein OT, Kronenburg A, Frassoldati A, Faravelli T, Deng L, Kempf AM, Vascellari M, Hasse C. Resolved flow simulation of pulverized coal particle devolatilization and ignition in air-and O2/CO2atmospheres. Fuel, 2016, 186: 285-292.

[29] Puri IK. Second law analysis of convective droplet burning. International Journal of Heat and Mass Transfer, 1992, 35(10): 2571-2578.

[30] Dash SK, Som SK. Transport processes and associated irreversibilities in droplet combustion in a convective medium. International Journal of Energy Research, 1991, 15(7): 603-619.

[31] Hiwase SD, Datta A, Som SK. Entropy balance and exergy analysis of the process of droplet combustion. Journal of Physics D: Applied Physics, 1998, 31: 1601-1610.

[32] Raghavan V, Gogos G, Babu V, Sundararajan T. Entropy generation during the quasi-steady burning of spherical fuel particles. International Journal of Thermal Sciences, 2007, 46(6): 589-604.

[33] Pope DN, Raghavan V, Gogos G. Gas-phase entropy generation during transient methanol droplet combustion. International Journal of Thermal Sciences, 2010, 49(7): 1288-1302.

[34] Som SK, Mondal SS, Dash SK. Energy and exergy balance in the process of pulverized coal combustion in a tubular combustor. Journal of Heat Transfer, 2005, 127(12): 1322-1333. 
[35] Mondal SS. Modelling of transport processes and associated thermodynamic irreversibilities in ignition and combustion of a pulverized coal particle. International Journal of Thermal Sciences, 2008, 47(11): 14421453.

[36] Baloyi J, Bello-Ochende T, Meyer JP. Thermodynamic optimisation and computational analysis of irreversibilities in a small-scale wood-fired circulating fluidised bed adiabatic combustor. Energy, 2014, 70: 653-663.

[37] Wang LW, Karimi N, Paul MC. Gas-phase transport and entropy generation during transient combustion of single biomass particle in varying oxygen and nitrogen atmospheres. International Journal of Hydrogen Energy, 2018, 43(17), 8506-8523.

[38] Hurt RH. Structure, properties and reactivity of solids fuels. In: 27th Symposium (International) on Combustion, The Combustion Institute, 1998: 2887-2904.

[39] Badzioch S, Hawksley PGW. Kinetics of thermal decomposition of pulverized coal particles. Industrial \& Engineering Chemistry Process Design and Development, 1970, 9(4):521-530.

[40] ANSYS Fluent Theory Guide 15.0. 2013.

[41] Chen X, Horio M, Kojima T. Numerical simulation of entrained flow coal gasifiers. Part I: modeling of coal gasification in an entrained flow gasifier. Chemical Energy Science, 2000, 55: 3861-3874.

[42] Mayers AM. The rate of reduction of carbon dioxide by graphite. Journal of the American Chemical Society, 1934, 56:70-76.

[43] Blaid S, Paul MC, Watson IA. Numerical investigation of the heterogeneous combustion processes of solid fuels. Fuel, 2015, 141:236-249.

[44] Jenkinsa BM, Baxterb LL, Miles TR. Combustion properties of biomass. Fuel Processing Technology, 1998, 54(1-3): 17-46.

[45] Morsi SA, Alexander AJ. An investigation of particle trajectories in two-phase flow systems. Journal of Fluid Mechanics, 1972, 55(2): 193-208.

[46] Blaid S. Ph.D. thesis. Numerical investigation of the combustion processes of various fuels. University of Glasgow, 2015.

[47] Howard JB, Williams GC, Fine DH. Kinetics of carbon monoxide oxidation in postflame gases. Proceedings of 14th Symposium (International) on Combustion, 1973: 975-986.

[48] Serio MA, Hamblen DG, Markham JR, Solomon PR. Kinetics of volatile product evolution in coal pyrolysis: experiment and theory. Energy \& Fuels, 1987, 1:138-152.

[49] Levendis YA, Estrada KR. "Development of multicolour pyrometers to monitor the transient response of burning carbonaceous particles.” Review of Scientific Instruments, 1992, 63:3608-3622.

[50] Khatami R, Levendis YA. "On the deduction of single coal particle combustion temperature from three-color optical pyrometry." Combustion and Flame, 2011, 158(9):1822-1836.

[51] Williams FA. Combustion Theory, second ed. Benjamin/Cummings, Menlo Park, California, 1985.

[52] Hirschfelder JO, Curtiss CF, Bird RB. Molecular Theory of Gases and Liquids. Wiley, New York, 1954.

[53] Carrington CG, Sun ZF. Second law analysis of combined heat and mass transfer phenomena. International Journal of Heat and Mass Transfer, 1991, 34(11):2767-2773. 
Tables:

Table 1 Coal Analysis Data [10][11][12]

\begin{tabular}{ll}
\hline Fuel & $\begin{array}{l}\text { DECS-11 } \\
\text { (Lignite) }\end{array}$ \\
\hline Proximate analysis (received) & \\
Moisture (\%) & 13.2 \\
Volatile (\%) & 48.6 \\
Fixed Carbon (\%) & 29.8 \\
Ash (\%) & 8.4 \\
& \\
Ultimate analysis (dry basis) & \\
C & 66.2 \\
H & 4.0 \\
O & 18.6 \\
$\mathrm{~N}$ & 0.9 \\
S & 0.7 \\
Ash & 9.6 \\
Heating value dry fuel (MJ/kg) & 25.7 \\
\hline
\end{tabular}

Table 2 Operating Conditions [10][11][12]

\begin{tabular}{lll}
\hline Parameters & \multicolumn{2}{c}{ Values } \\
\cline { 2 - 3 } & Quiescent Flow & Active Flow \\
\hline Wall Temperature & $1400 \mathrm{~K}$ & $1400 \mathrm{~K}$ \\
Temperature of injecting gas & $1200 \mathrm{~K}$ & $1200 \mathrm{~K}$ \\
Velocity of gas & 0 & $4.55 \mathrm{~cm} / \mathrm{s}$ \\
Diameter of particles & $80 \mu \mathrm{m}$ & $80 \mu \mathrm{m}$ \\
Initial temperature of particles & $750 \mathrm{~K}$ & $1050 \mathrm{~K}$ \\
Velocity of particles & $15 \mathrm{~cm} / \mathrm{s}$ & $15 \mathrm{~cm} / \mathrm{s}$ \\
Oxygen concentration & $20 \%, 40 \%, 60 \%, 21 \%, 37 \%, 68 \%$, \\
& $80 \%, 100 \%$ & $100 \%$ \\
\hline
\end{tabular}

Table 3 Kinetic constants

\begin{tabular}{l|l|l|l|l|l|l}
\hline \multirow{2}{*}{$\begin{array}{l}\text { Reaction } \\
\text { NO. }\end{array}$} & \multicolumn{3}{|c|}{ Kinetic parameters } & $d$ & $e$ & Ref. \\
\cline { 2 - 4 } & \multicolumn{1}{|c|}{$\mathrm{A}$} & \multicolumn{1}{c|}{$\mathrm{E}$} & & & & \\
\hline R1 & $3.12 \mathrm{E}+05$ & $7.4 \mathrm{E}+07$ & - & - & - & {$[40]$} \\
R2 & 0.002 & $7.9 \mathrm{E}+07$ & 0 & - & - & {$[40]$} \\
R3 & 0.052 & $1.33 \mathrm{E}+08$ & 0 & - & - & {$[41]$} \\
R4 & 4.4 & $1.62 \mathrm{E}+08$ & 1 & - & - & {$[42]$} \\
R5 & 1.33 & $1.47 \mathrm{E}+08$ & 1 & - & - & {$[42]$} \\
R6 & $2.119 \mathrm{E}+11$ & $2.027 \mathrm{E}+08$ & - & 0.2 & 1.3 & {$[40]$} \\
R7 & $1.30 \mathrm{E}+11$ & $1.26 \mathrm{E}+08$ & - & 0.5 & 0.5 & {$[47]$} \\
R8 & $5.69 \mathrm{E}+11$ & $1.465 \mathrm{E}+08$ & - & 1 & 0.5 & {$[48]$} \\
\hline
\end{tabular}


Table 4 Comparison between the numerical and experimental data

\begin{tabular}{|c|c|c|c|c|c|c|c|c|c|}
\hline \multirow{2}{*}{$\begin{array}{l}\text { Gas } \\
\text { Conditions }\end{array}$} & \multicolumn{3}{|c|}{ Ignition Delay Time (ms) } & \multicolumn{3}{|c|}{ Particle Life Time (ms) } & \multicolumn{3}{|c|}{$\begin{array}{l}\text { Particle Maximum Temperature } \\
\qquad(\mathrm{K})\end{array}$} \\
\hline & $\begin{array}{l}\text { Experiment } \\
{[10][11][12]}\end{array}$ & $\begin{array}{l}\text { Numerical } \\
\text { Simulations }\end{array}$ & $\begin{array}{c}\text { Error } \\
(\%)\end{array}$ & $\begin{array}{l}\text { Experiment } \\
{[10][11][12]}\end{array}$ & $\begin{array}{l}\text { Numerical } \\
\text { Simulations }\end{array}$ & $\begin{array}{c}\text { Error } \\
(\%)\end{array}$ & $\begin{array}{c}\text { Experiment } \\
{[10][11][12]}\end{array}$ & $\begin{array}{l}\text { Numerical } \\
\text { Simulations }\end{array}$ & $\begin{array}{c}\text { Error } \\
(\%)\end{array}$ \\
\hline \multicolumn{10}{|c|}{ Quiescent Flow } \\
\hline $\begin{array}{l}20 \% \mathrm{O}_{2} \\
80 \% \mathrm{~N}_{2}\end{array}$ & 15.8 & 16.2 & 2.53 & 75.3 & 76.8 & 1.99 & 2302.8 & 2096.39 & 8.96 \\
\hline $\begin{array}{l}30 \% \mathrm{O}_{2} \\
70 \% \mathrm{~N}_{2}\end{array}$ & 17.2 & 17.4 & 1.16 & 58.5 & 57.2 & 2.22 & 2406.5 & 2367.09 & 1.63 \\
\hline $\begin{array}{l}40 \% \mathrm{O}_{2} \\
60 \% \mathrm{~N}_{2} \\
\end{array}$ & 17.8 & 16.8 & 5.62 & 49.8 & 47.3 & 5.02 & 2612.5 & 2578.17 & 1.31 \\
\hline $\begin{array}{l}60 \% \mathrm{O}_{2} \\
40 \% \mathrm{~N}_{2}\end{array}$ & 14.3 & 13.7 & 4.19 & 37.2 & 38.4 & 3.22 & 2781.5 & 2699.93 & 2.93 \\
\hline $\begin{array}{l}80 \% \mathrm{O}_{2} \\
20 \% \mathrm{~N}_{2}\end{array}$ & 13.4 & 13.1 & 2.24 & 30.9 & 33.2 & 7.44 & 3054.8 & 3033.65 & 0.69 \\
\hline $100 \% \mathrm{O}_{2}$ & 10.8 & 11.5 & 6.48 & 27.1 & 28.4 & 4.79 & 3092.6 & 3070.95 & 0.70 \\
\hline \multicolumn{10}{|l|}{ Active Flow } \\
\hline $\begin{array}{l}21 \% \mathrm{O}_{2} \\
79 \% \mathrm{~N}_{2}\end{array}$ & 4.9 & 5.1 & 4.08 & 42.3 & 41.9 & 0.94 & 2008.4 & 1972.85 & 1.77 \\
\hline $\begin{array}{l}37 \% \mathrm{O}_{2} \\
63 \% \mathrm{~N}_{2}\end{array}$ & 6.2 & 6.5 & 4.83 & 31.8 & 32.7 & 2.83 & 2397.5 & 2385.15 & 0.52 \\
\hline $\begin{array}{l}68 \% \mathrm{O}_{2} \\
32 \% \mathrm{~N}_{2} \\
\end{array}$ & 5.9 & 5.5 & 6.80 & 18.6 & 17.1 & 8.06 & 2952.4 & 2919.96 & 1.10 \\
\hline $100 \% \mathrm{O}_{2}$ & 6.3 & 5.9 & 6.35 & 19.3 & 19.2 & 0.52 & 2895.4 & 2889.13 & 0.22 \\
\hline
\end{tabular}




\section{Figures:}

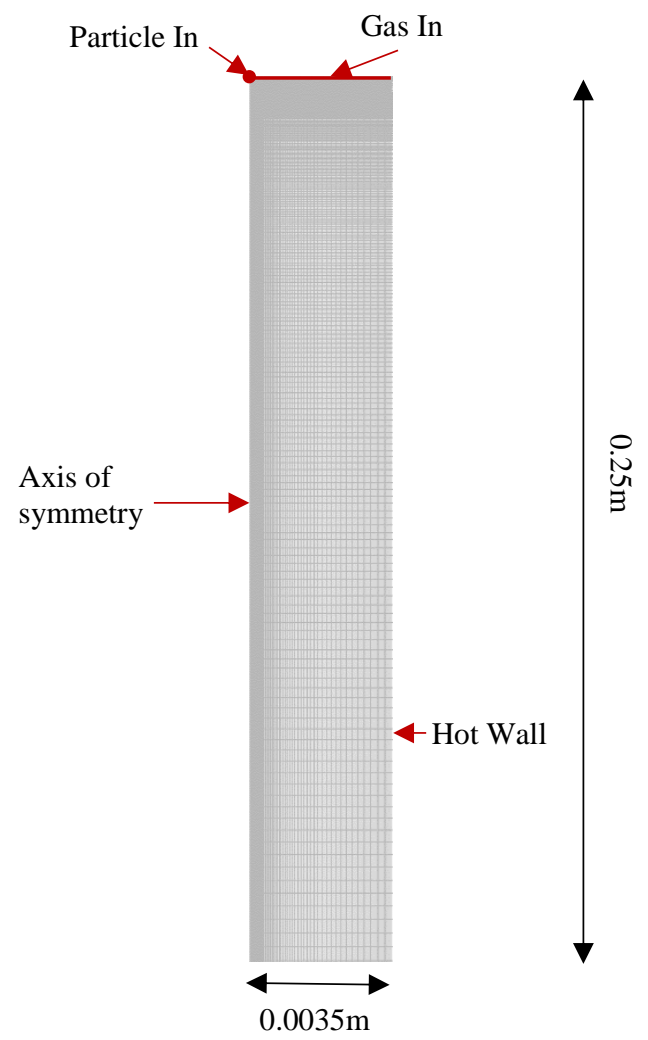

Fig. 1: Schematic of the computational domain 
(a)

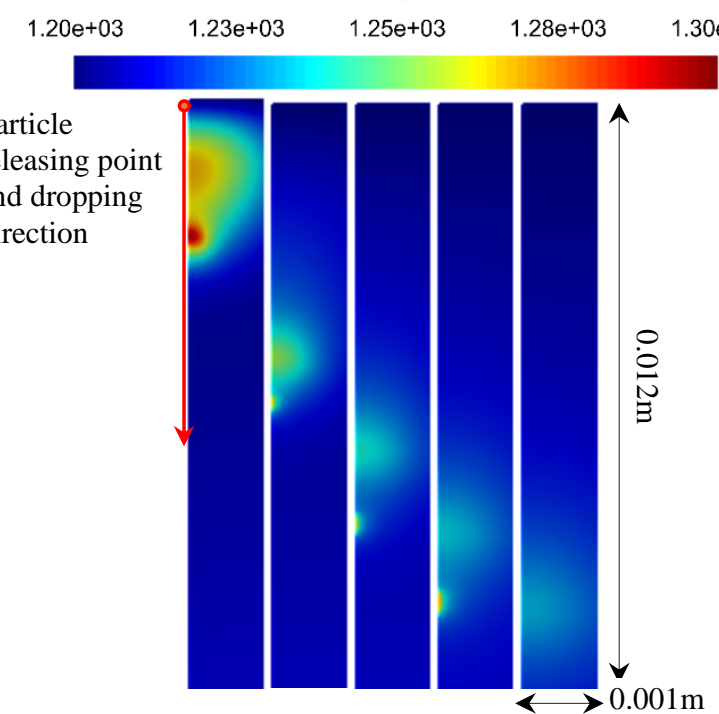

(b)

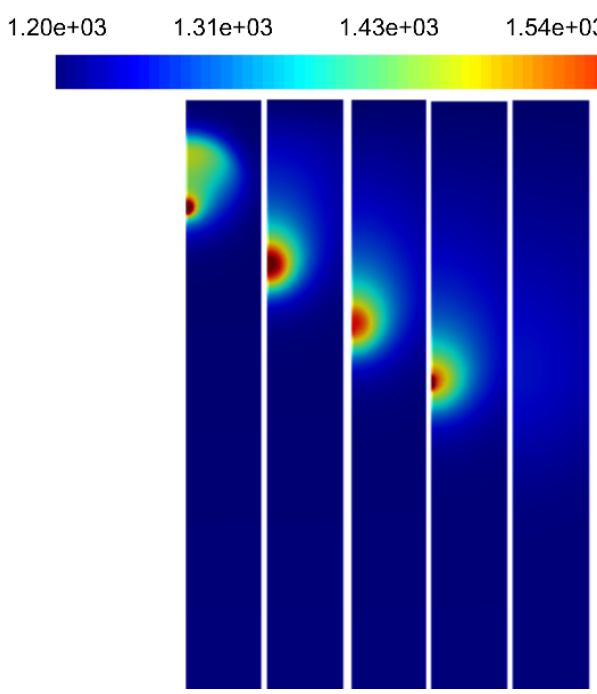

(c)

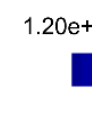

$1.24 \mathrm{e}+03$

$1.28 \mathrm{e}+03$

$1.31 \mathrm{e}+03$

$1.35 \mathrm{e}+03$

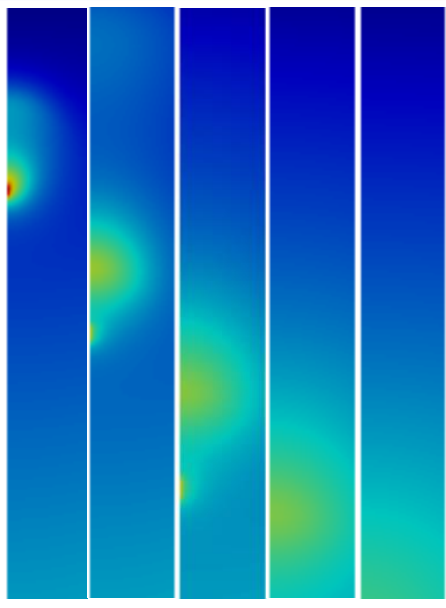

(d)

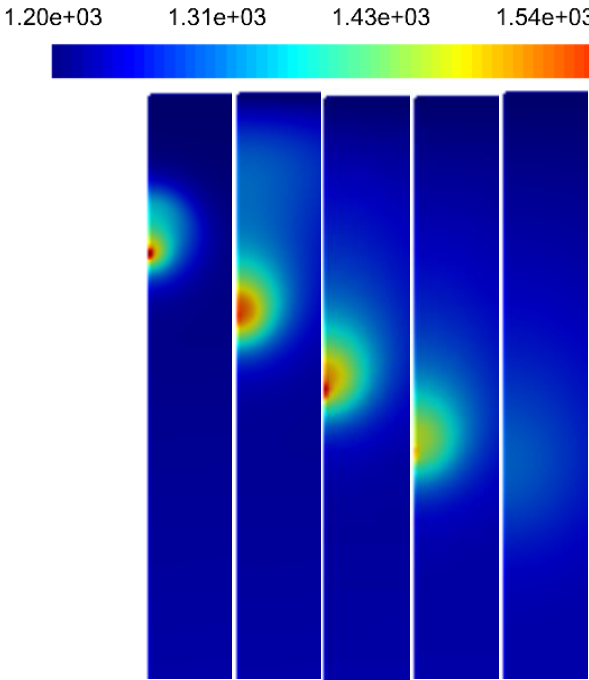

Fig. 2: Spatio-temporal distribution of the gas temperature. (a)-(b): active flow, $21 \% \mathrm{O}_{2} \& 79 \% \mathrm{~N}_{2}$ (9ms, 19ms,29ms,39ms,49ms), $100 \% \mathrm{O}_{2}$ (7ms, $\left.11 \mathrm{~ms}, 15 \mathrm{~ms}, 19 \mathrm{~ms}, 23 \mathrm{~ms}\right)$. (c)-(d): quiescent flow, $40 \% \mathrm{O}_{2} \& 60 \% \mathrm{~N}_{2}$ (20ms,30ms, $40 \mathrm{~ms}, 50 \mathrm{~ms}, 60 \mathrm{~ms}), 80 \% \mathrm{O}_{2} \& 20 \% \mathrm{~N}_{2}(14 \mathrm{~ms}, 20 \mathrm{~ms}, 26 \mathrm{~ms}, 32 \mathrm{~ms}, 38 \mathrm{~ms})$. 
(a)

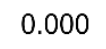

0.015

\begin{abstract}
0.0300
\end{abstract}
0.0450

0.0600

(b) $\quad 0.000$

0.0250

$0.0500 \quad 0.0750$

0.100
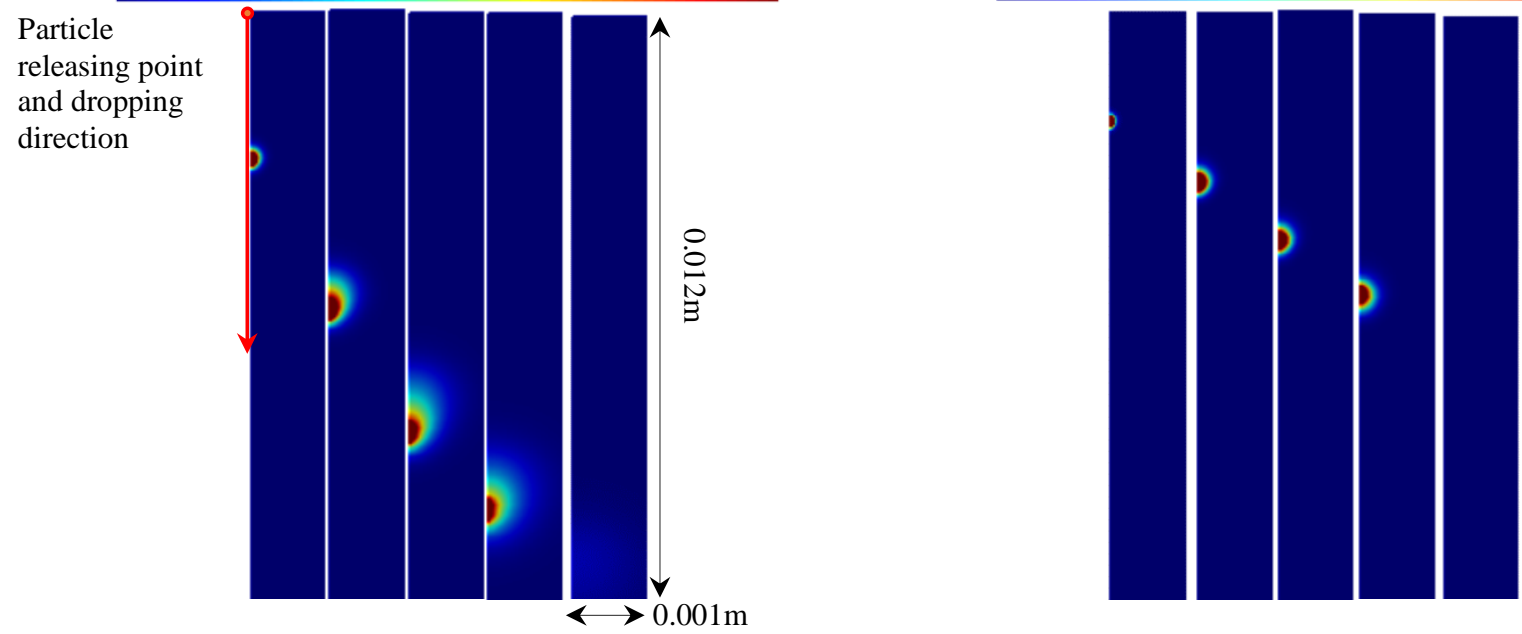

Fig. 3: Spatio-temporal distribution of $\mathrm{CO}$ under active flow, (a) $21 \% \mathrm{O}_{2} \& 79 \% \mathrm{~N}_{2}(9 \mathrm{~ms}, 19 \mathrm{~ms}, 29 \mathrm{~ms}, 39 \mathrm{~ms}, 49 \mathrm{~ms})$, (b) $100 \% \mathrm{O}_{2}(7 \mathrm{~ms}, 11 \mathrm{~ms}, 15 \mathrm{~ms}, 19 \mathrm{~ms}, 23 \mathrm{~ms})$. 


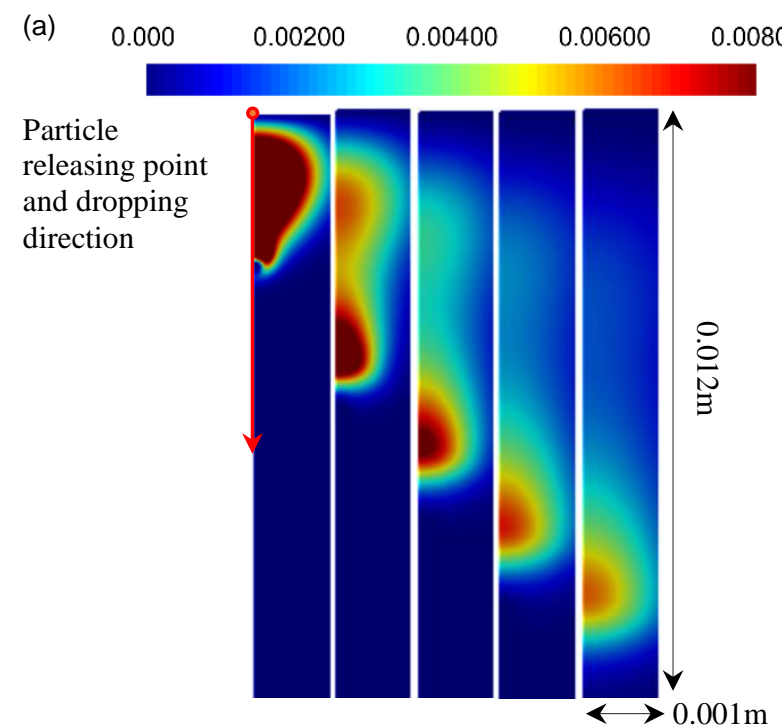

(b) $\quad 0.000$

Fig. 4: Spatio-temporal distribution of $\mathrm{CO}_{2}$ under active flow, (a) $21 \% \mathrm{O}_{2} \& 79 \% \mathrm{~N}_{2}(9 \mathrm{~ms}, 19 \mathrm{~ms}, 29 \mathrm{~ms}, 39 \mathrm{~ms}, 49 \mathrm{~ms})$, (b) $100 \% \mathrm{O}_{2}(7 \mathrm{~ms}, 11 \mathrm{~ms}, 15 \mathrm{~ms}, 19 \mathrm{~ms}, 23 \mathrm{~ms})$. 
(a) 0.000 0.0012 0.00250 0.00375 0.00500 (b) $\quad 0.000$ 0.00200 0.00400

Particle

releasing point and dropping direction
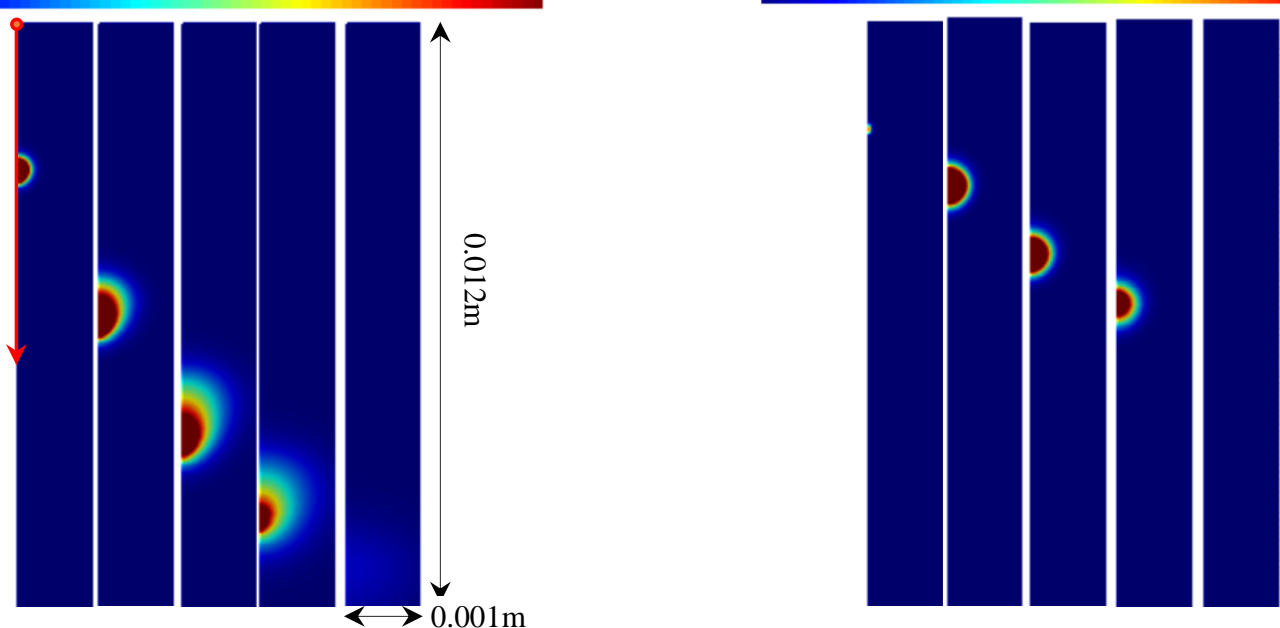

Fig. 5: Spatio-temporal distribution of $\mathrm{H}_{2}$ under active flow, (a) $21 \% \mathrm{O}_{2} \& 79 \% \mathrm{~N}_{2}(9 \mathrm{~ms}, 19 \mathrm{~ms}, 29 \mathrm{~ms}, 39 \mathrm{~ms}, 49 \mathrm{~ms})$, (b) $100 \% \mathrm{O}_{2}(7 \mathrm{~ms}, 11 \mathrm{~ms}, 15 \mathrm{~ms}, 19 \mathrm{~ms}, 23 \mathrm{~ms})$. 


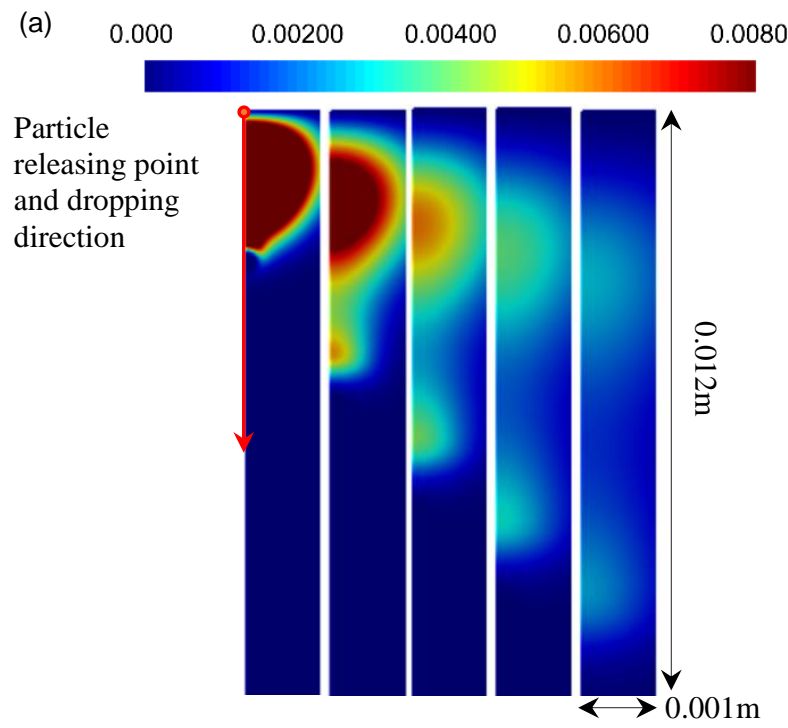

$\begin{array}{lllll}\text { (b) } \quad 0.000 & 0.00200 & 0.00400 & 0.00600 & 0.00800\end{array}$

Fig. 6: Spatio-temporal distribution of $\mathrm{H}_{2} \mathrm{O}$ under active flow, (a) $21 \% \mathrm{O}_{2} \& 79 \% \mathrm{~N}_{2}$ (9ms, $19 \mathrm{~ms}, 29 \mathrm{~ms}, 39 \mathrm{~ms}, 49 \mathrm{~ms}$ ), (b) $100 \% \mathrm{O}_{2}(7 \mathrm{~ms}, 11 \mathrm{~ms}, 15 \mathrm{~ms}, 19 \mathrm{~ms}, 23 \mathrm{~ms})$. 
(a)

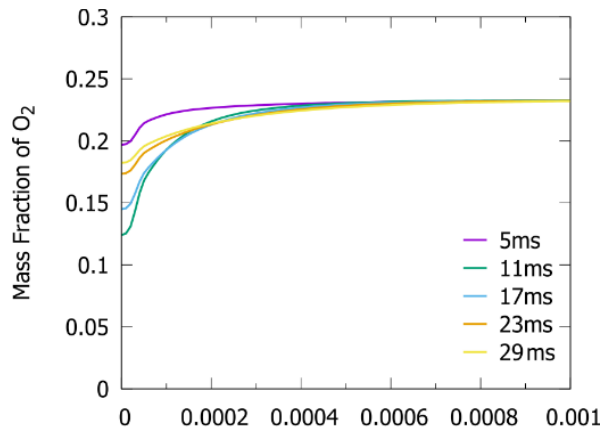

(b)

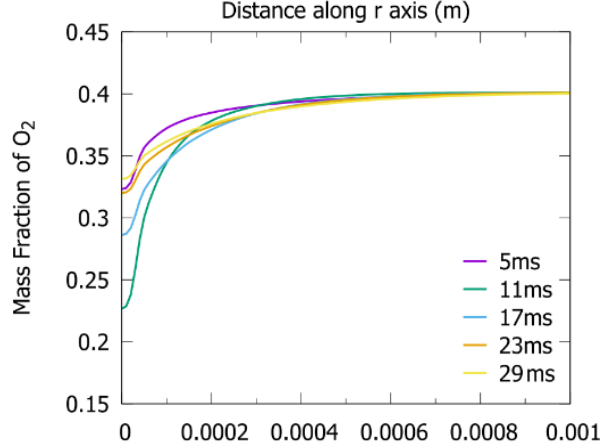

(c)

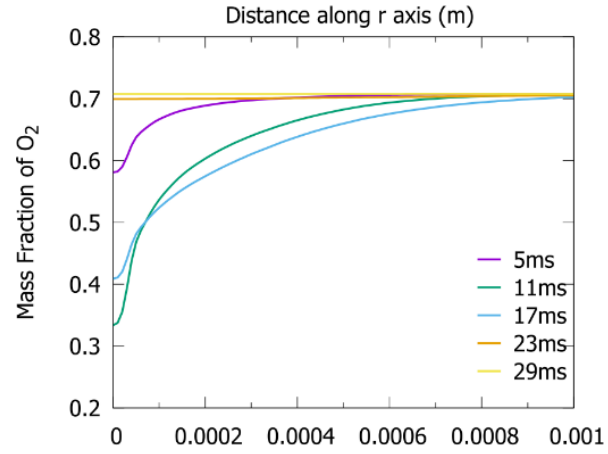

(d)

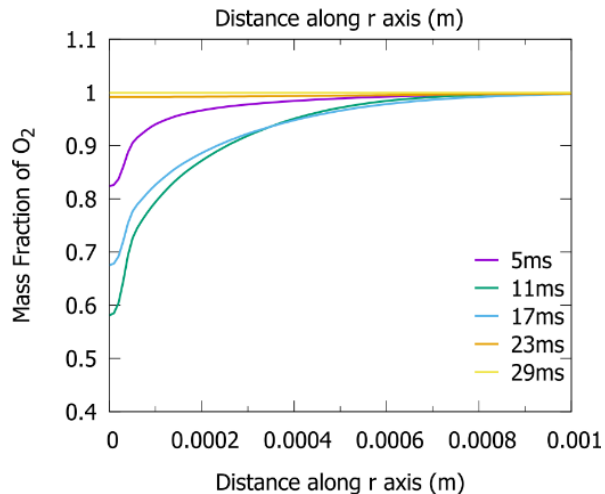

(e)

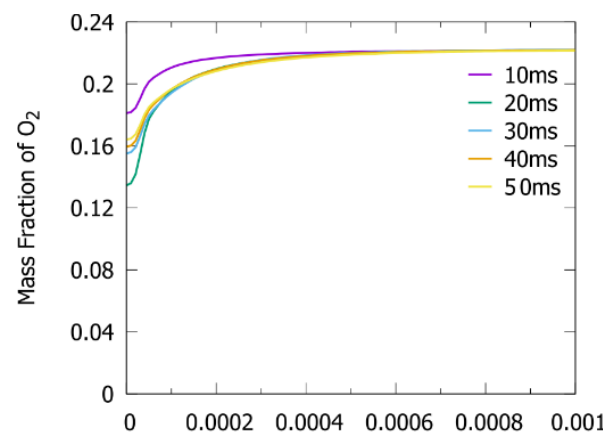

(f)

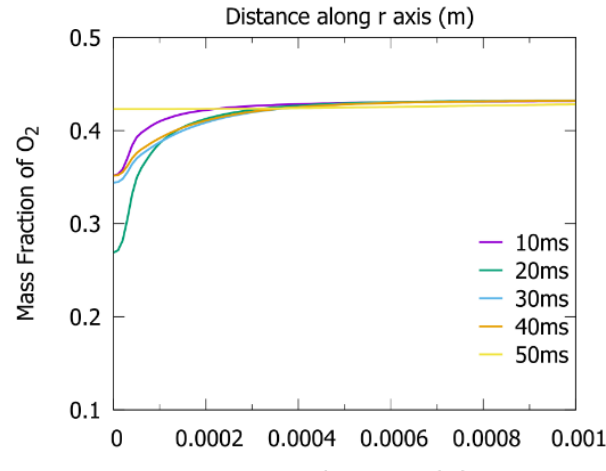

$(\mathrm{g})$

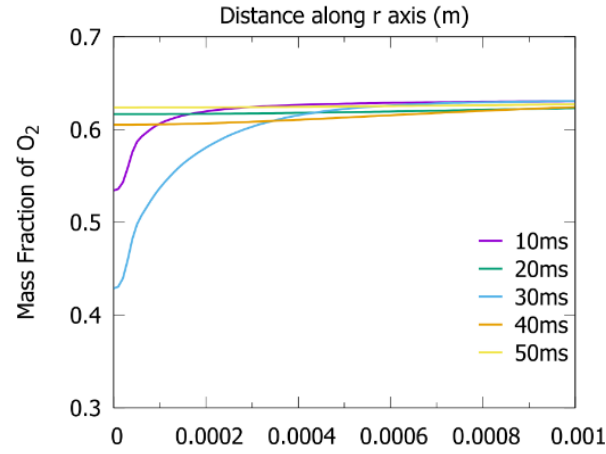

(h)

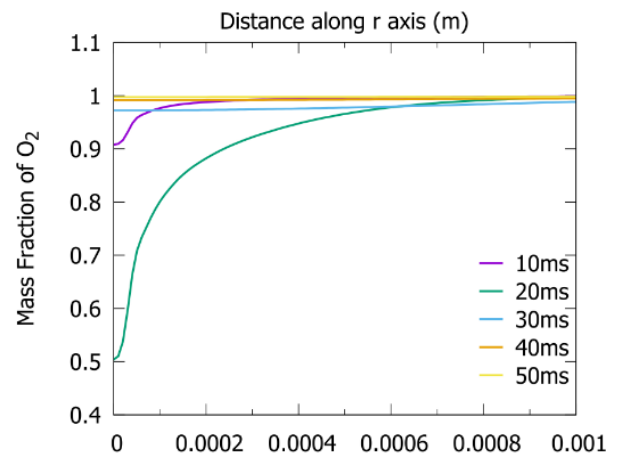

Distance along $r$ axis $(\mathrm{m})$

Fig. 7: distribution of oxygen mass fraction along a horizontal line initiating at the particle centre. (a)-(d): active flow, $21 \% \mathrm{O}_{2}, 37 \% \mathrm{O}_{2}, 68 \% \mathrm{O}_{2}, 100 \% \mathrm{O}_{2}$. (e)-(h): quiescent flow, $20 \% \mathrm{O}_{2}, 40 \% \mathrm{O}_{2}, 60 \% \mathrm{O}_{2}, 100 \% \mathrm{O}_{2}$. 
(a)

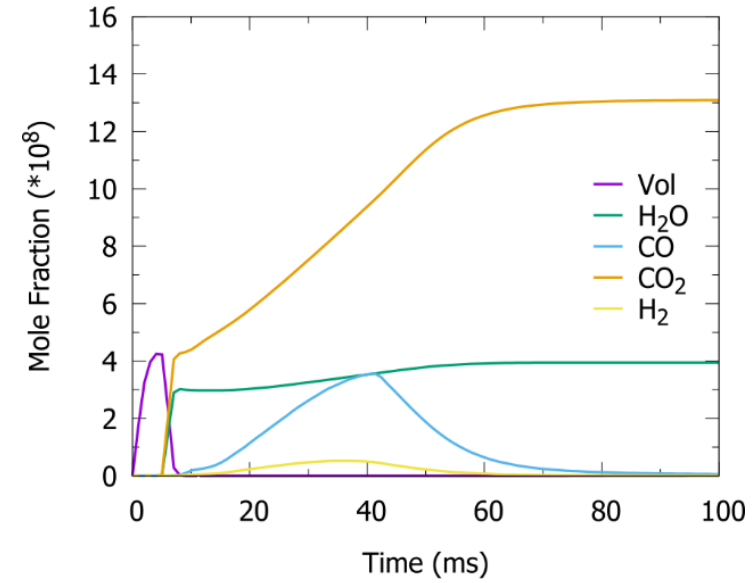

(b)

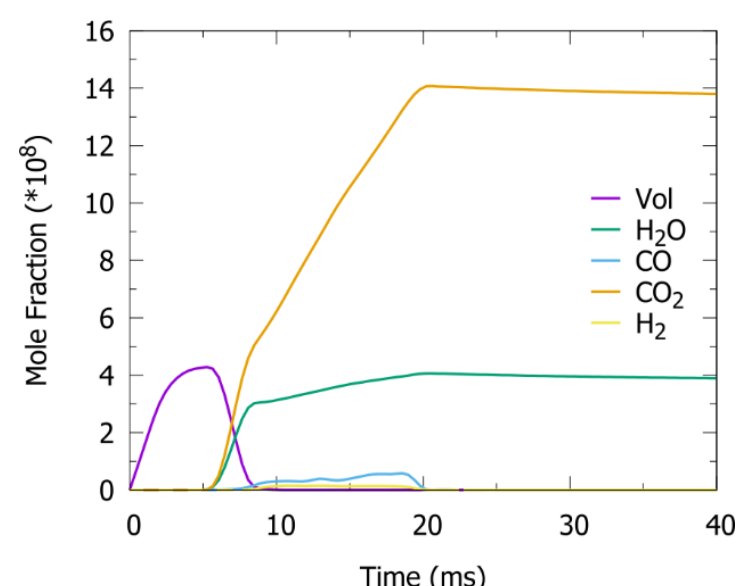

(c)

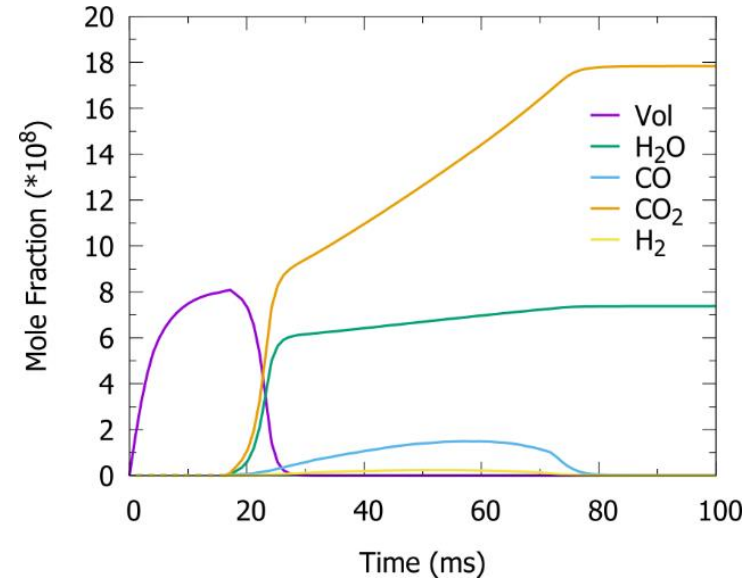

(d)

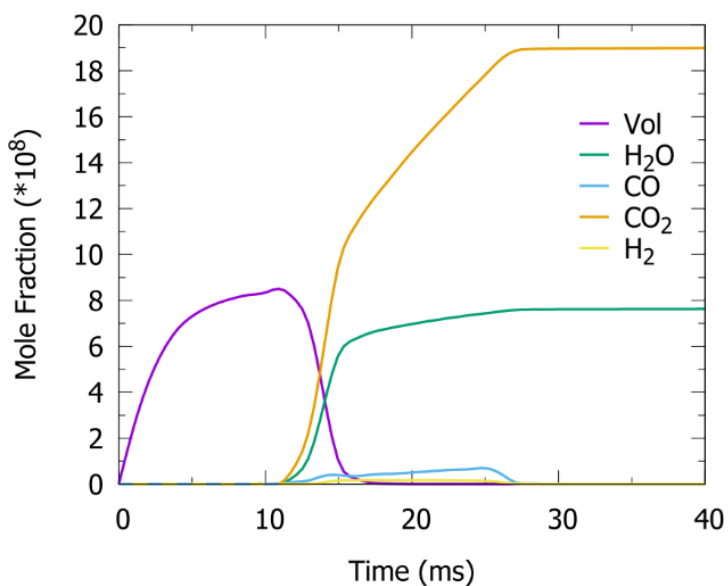

Fig. 8: History of mole fraction of major species, a) $21 \% \mathrm{O}_{2} \& 79 \% \mathrm{~N}_{2}$, active flow, b) $100 \% \mathrm{O}_{2}$, active flow, c) $20 \%$ $\mathrm{O}_{2} \& 80 \% \mathrm{~N}_{2}$, quiescent flow, d) $100 \% \mathrm{O} 2$, quiescent flow. 


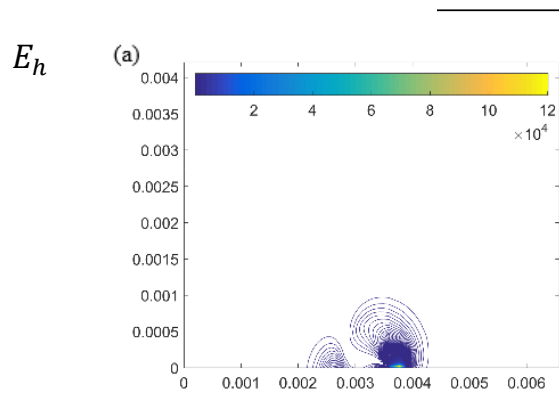

(d)

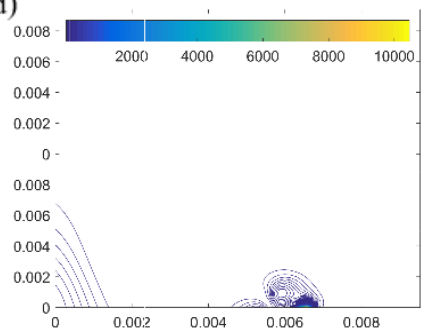

$E_{m}$

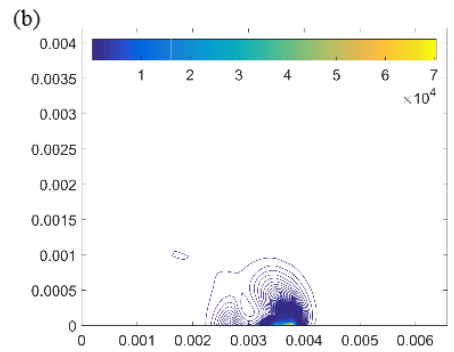

$E_{r}$

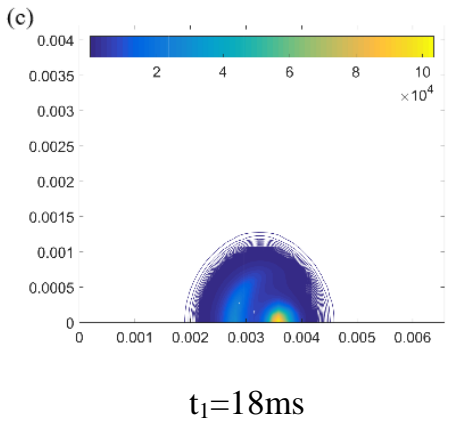

(e)

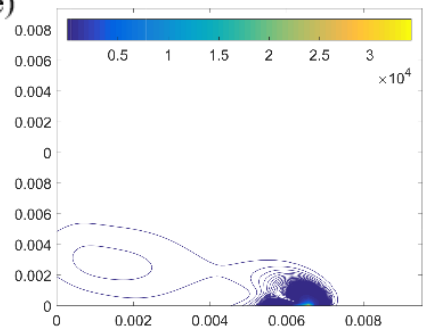

(f)

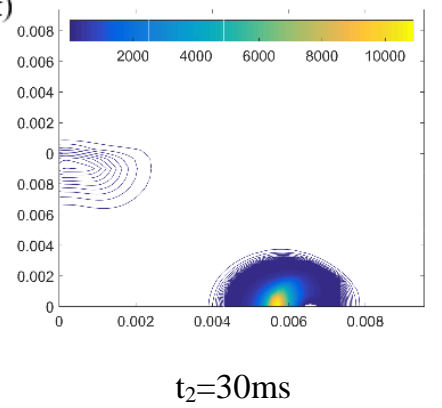

(g)

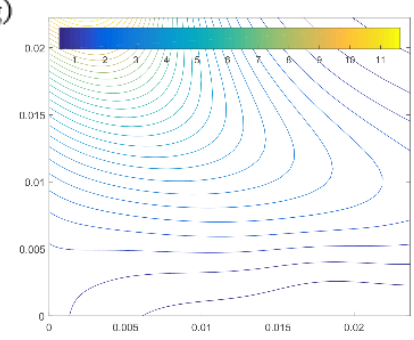

(h)

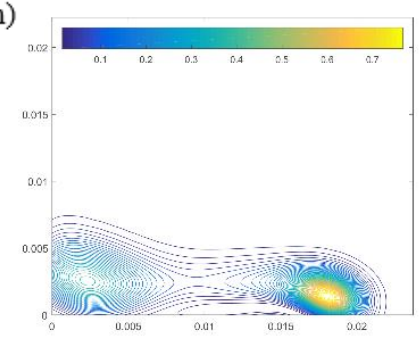

(i)

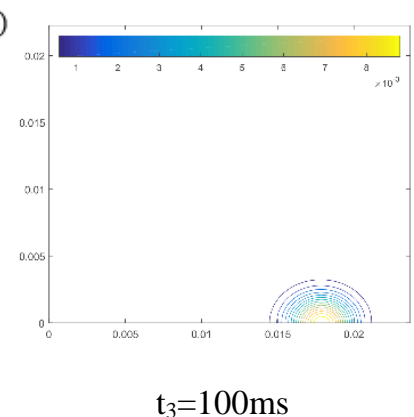

Fig. 9: Spatio-temporal evolution of entropy generation rate per unit volume under quiescent flow and for $20 \% \mathrm{O}_{2} \&$ $80 \% \mathrm{~N}_{2}$. 

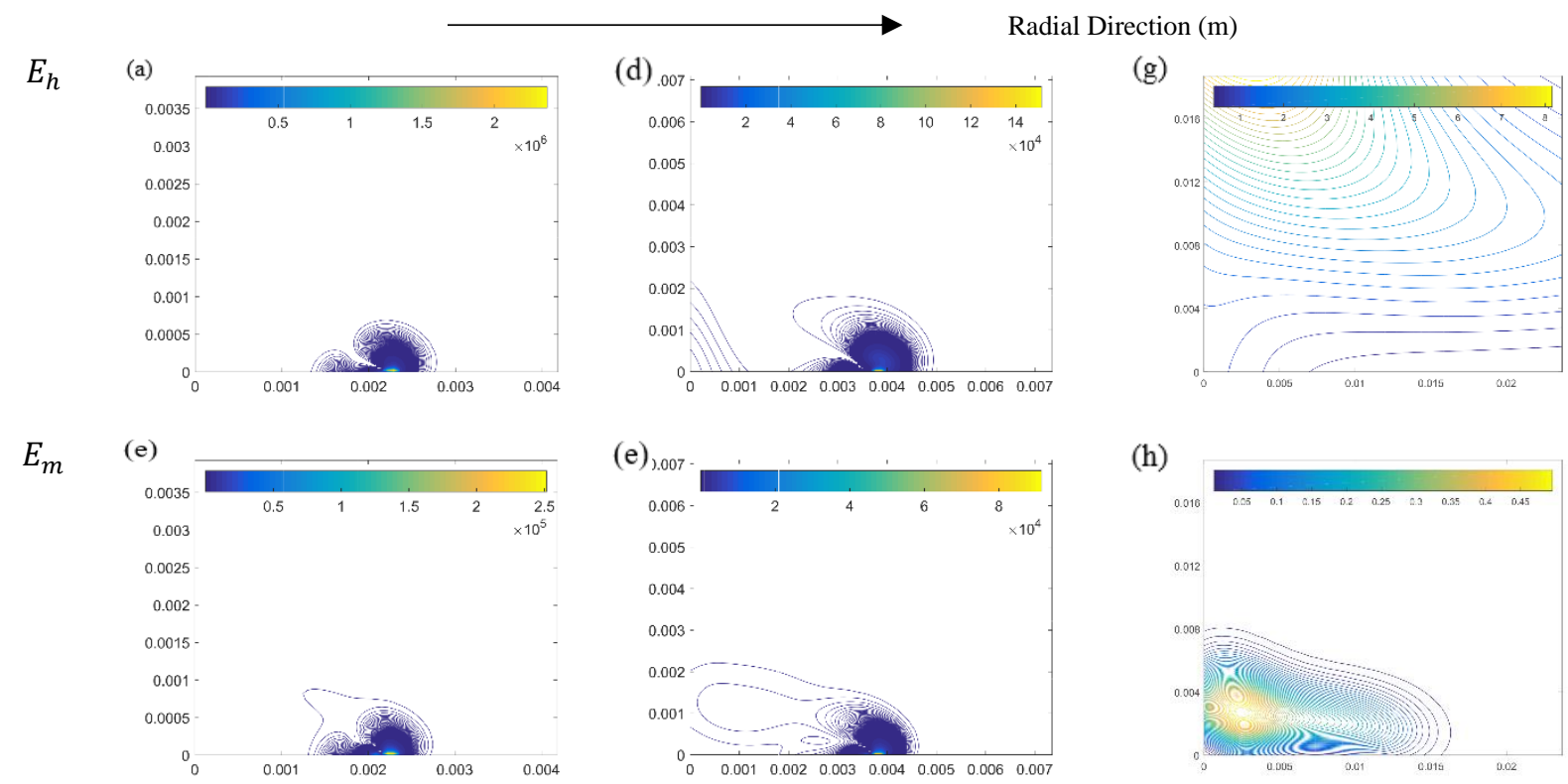

$E_{r}$
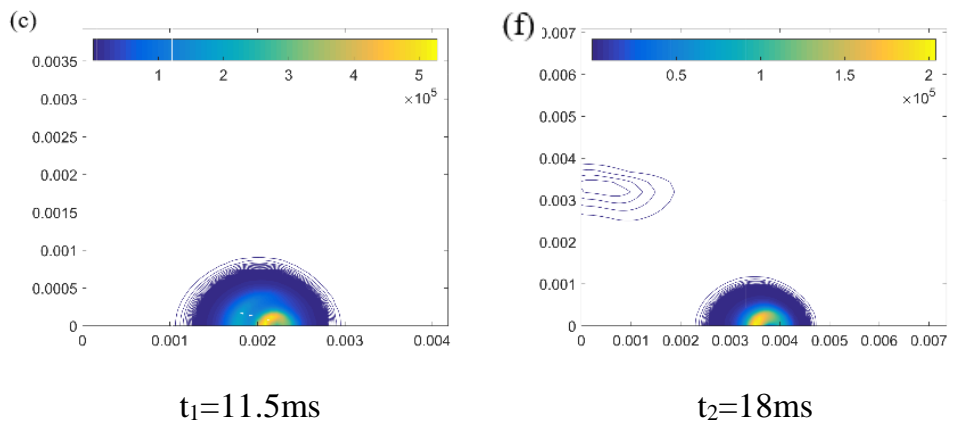

(i)

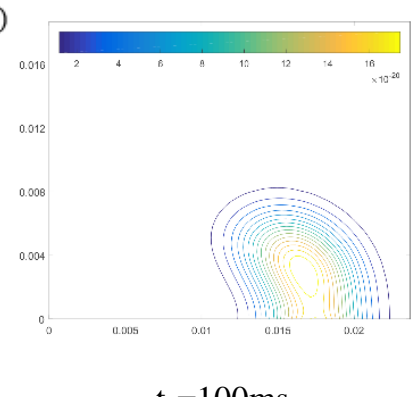

Fig. 10: Spatio-temporal evolution of entropy generation rate per unit volume under quiescent flow and for $100 \% \mathrm{O}_{2}$. 

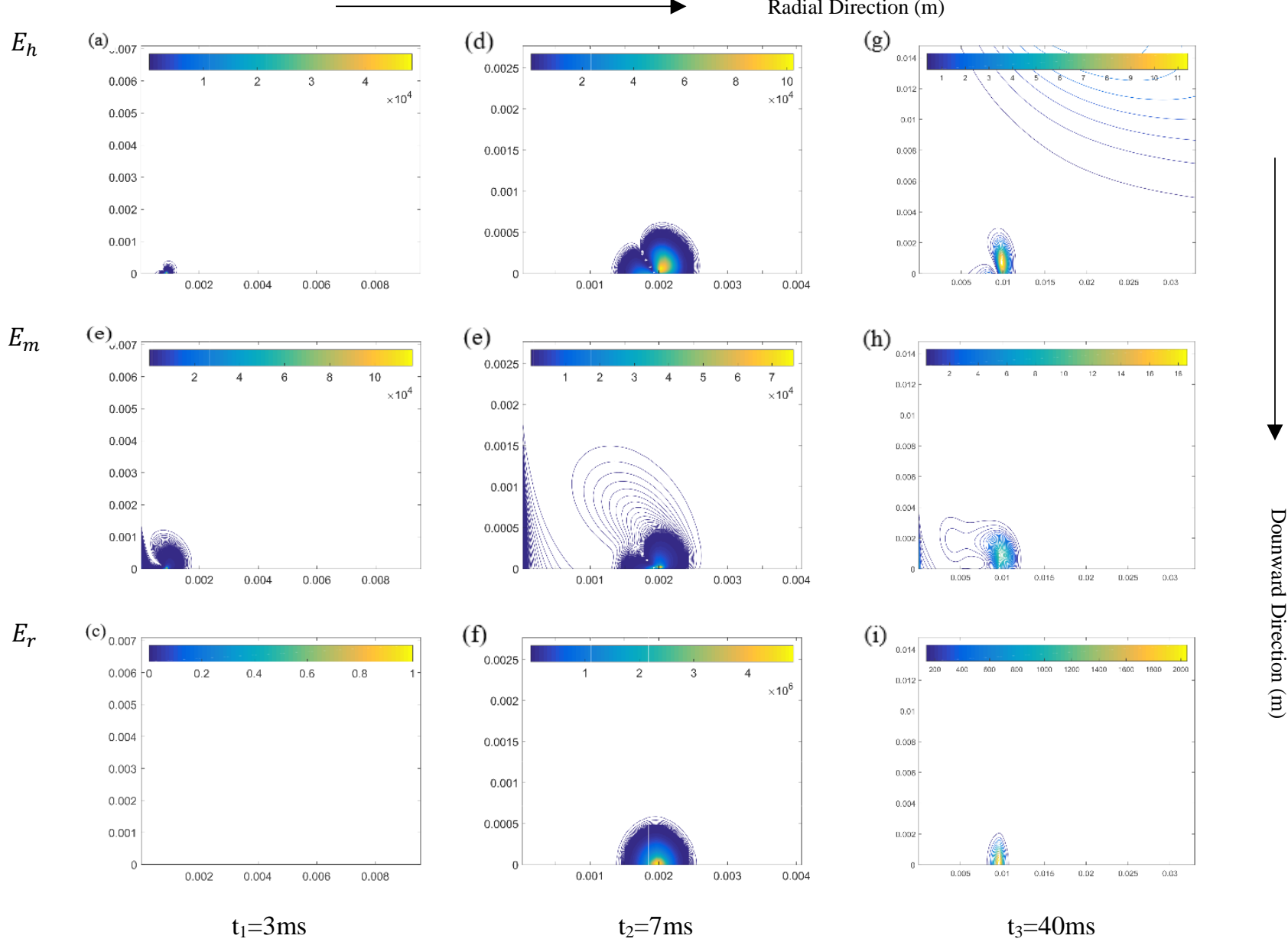

Fig 11. Spatio-temporal evolution of entropy generation rate per unit volume under active flow and for $37 \% \mathrm{O}_{2} \&$ $67 \% \mathrm{~N}_{2}$. 

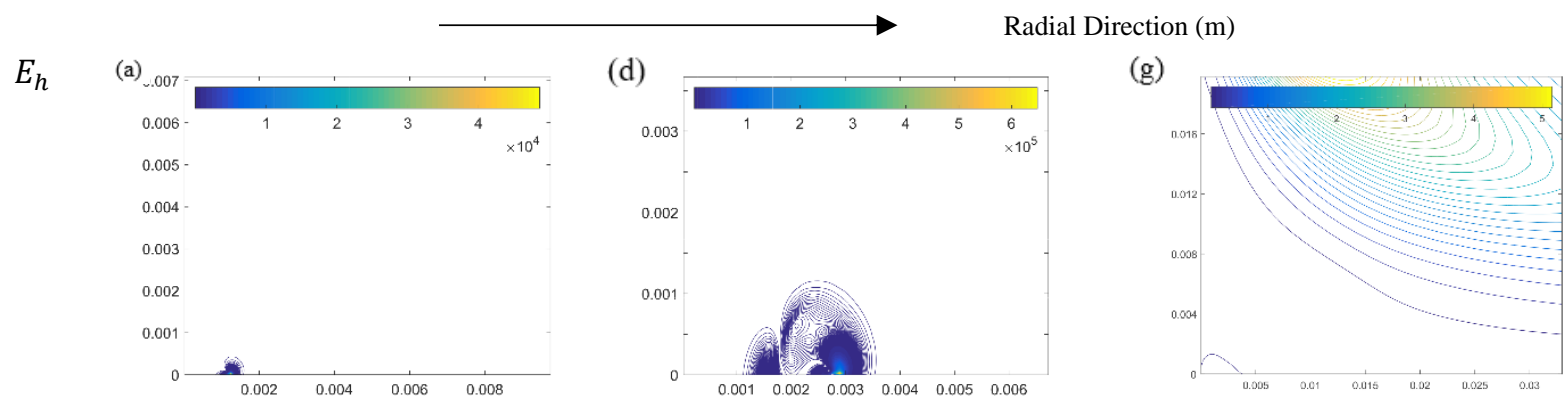

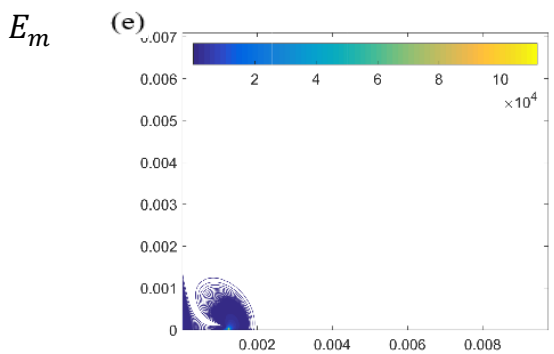

(e)

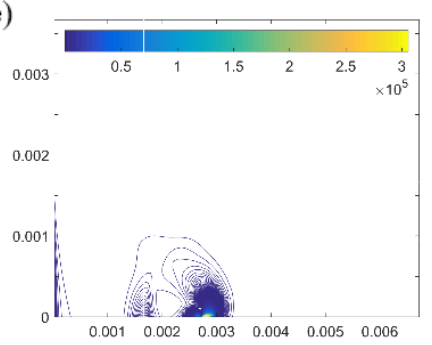

$E_{r}$

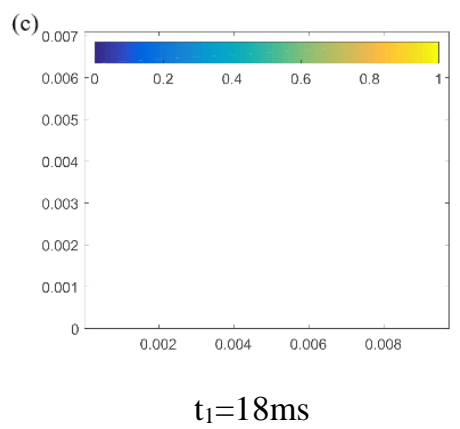

(f)

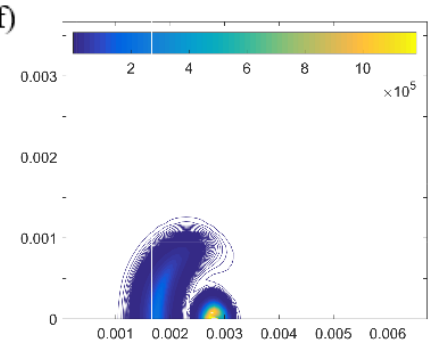

$\mathrm{t}_{2}=30 \mathrm{~ms}$ (h)

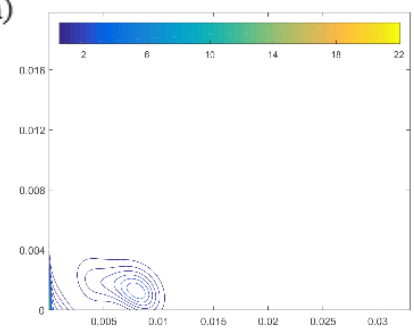

(i)

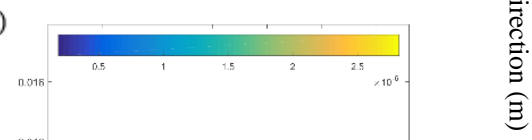

$\mathrm{t}_{3}=100 \mathrm{~ms}$

Fig 12: Spatio-temporal evolution of entropy generation rate per unit volume under active flow and for $68 \% \mathrm{O}_{2} \&$ $32 \% \mathrm{~N}_{2}$. 
(a)

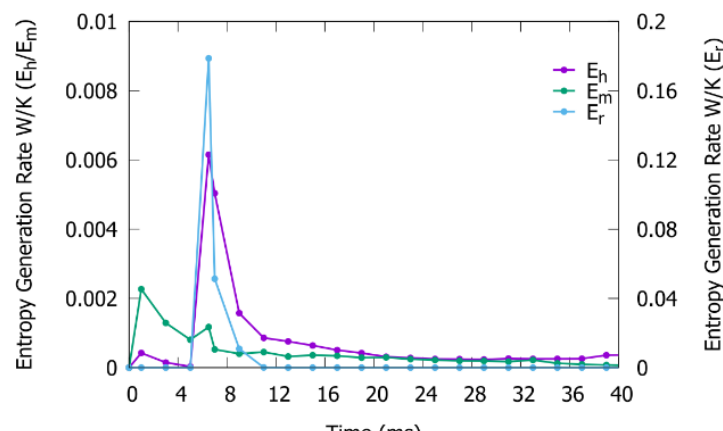

(c)

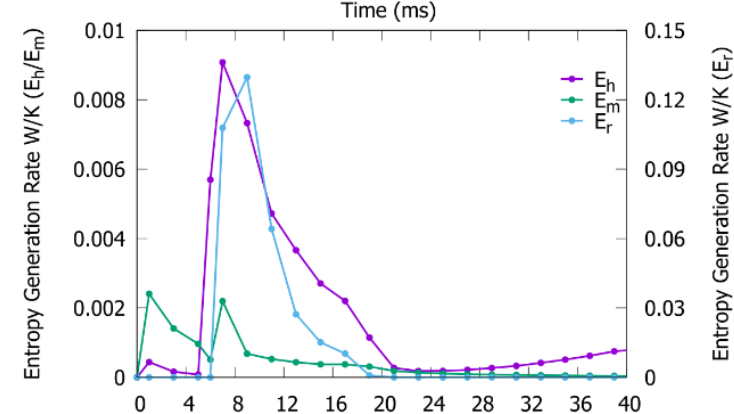

(e)

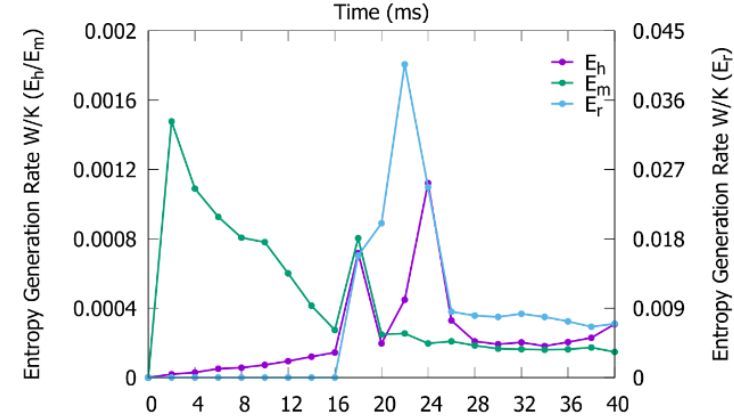

(g)

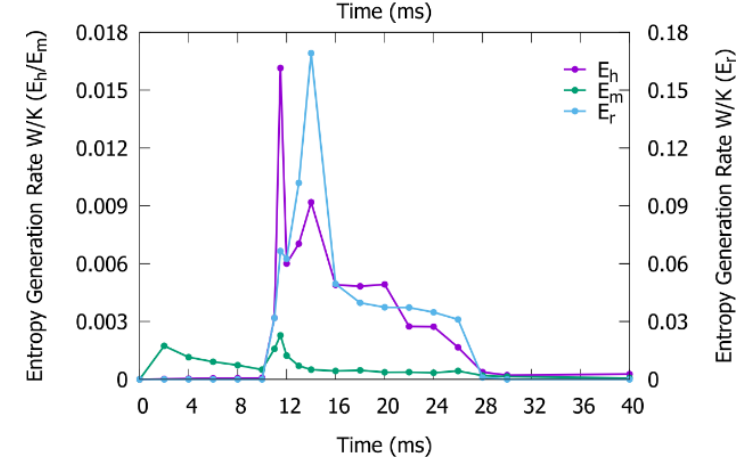

(b)

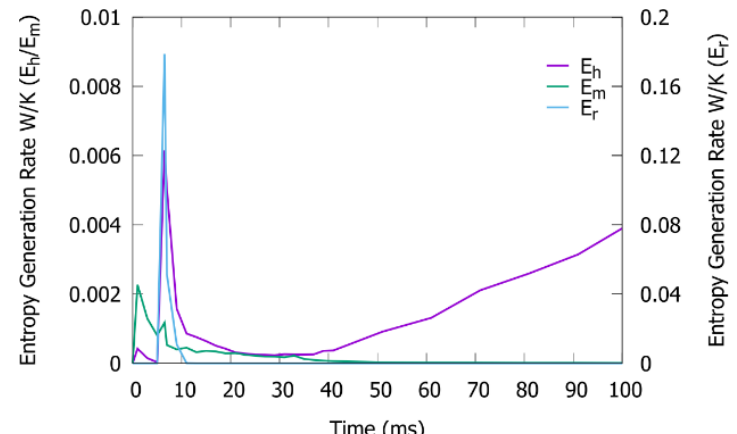

(d)

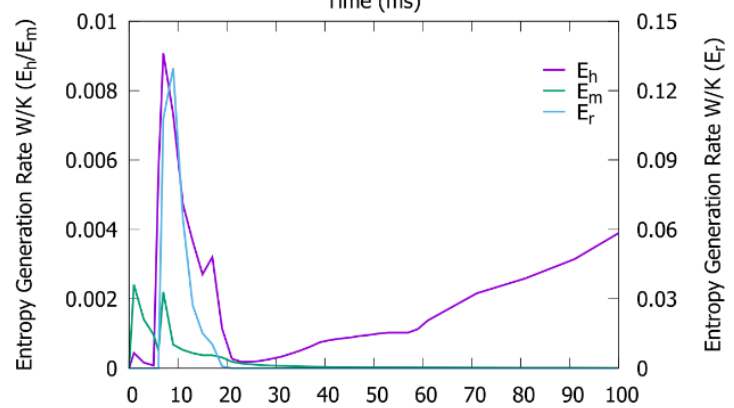

(f)

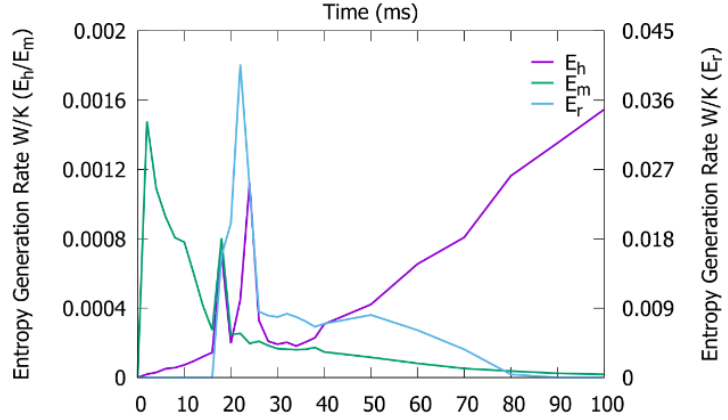

(h)

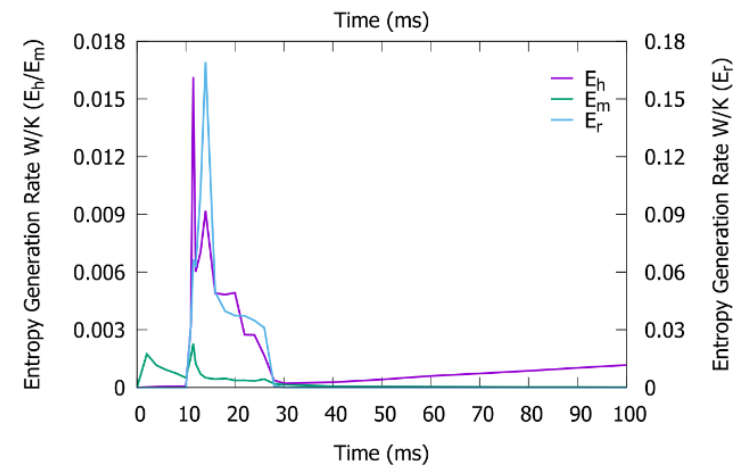

Fig. 13: History of entropy generation by different irreversibilities, left column provides zoomed in views of the graphs in the right column, (a)-(b): active flow, $37 \% \mathrm{O}_{2} \& 63 \% \mathrm{~N}_{2}$, (c)-(d): active flow, $68 \% \mathrm{O}_{2} \& 32 \% \mathrm{~N}_{2}$. (e)-(f): quiescent flow, $20 \% \mathrm{O}_{2} \& 80 \% \mathrm{~N}_{2}$, (g)-(h): quiescent flow, $100 \% \mathrm{O}_{2}$. 
(a)

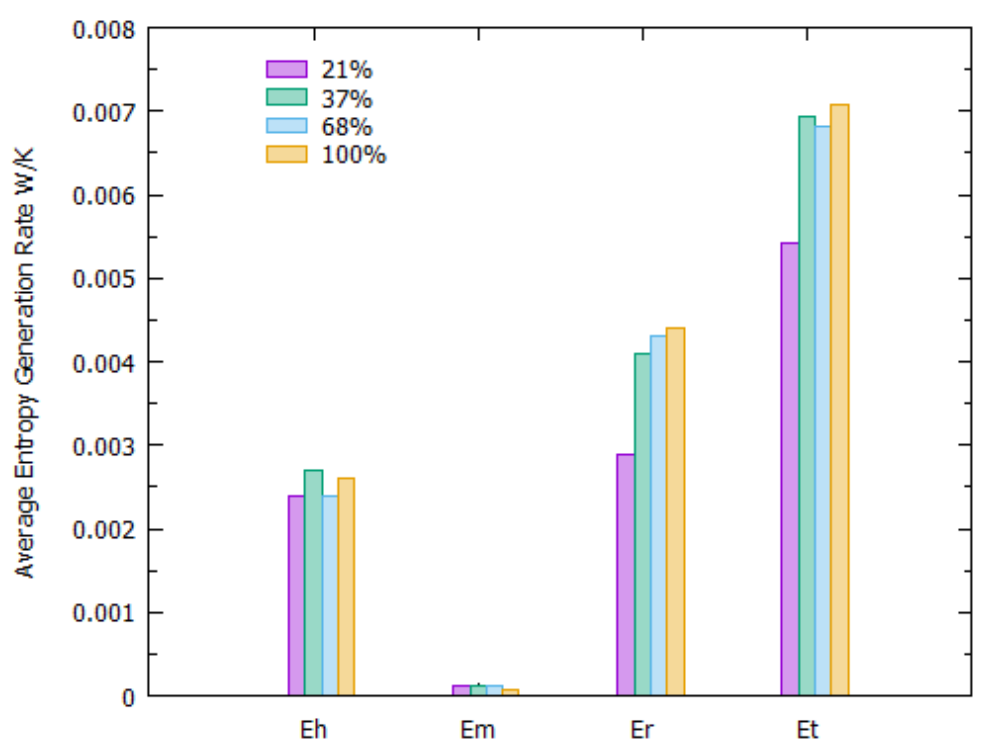

(b)

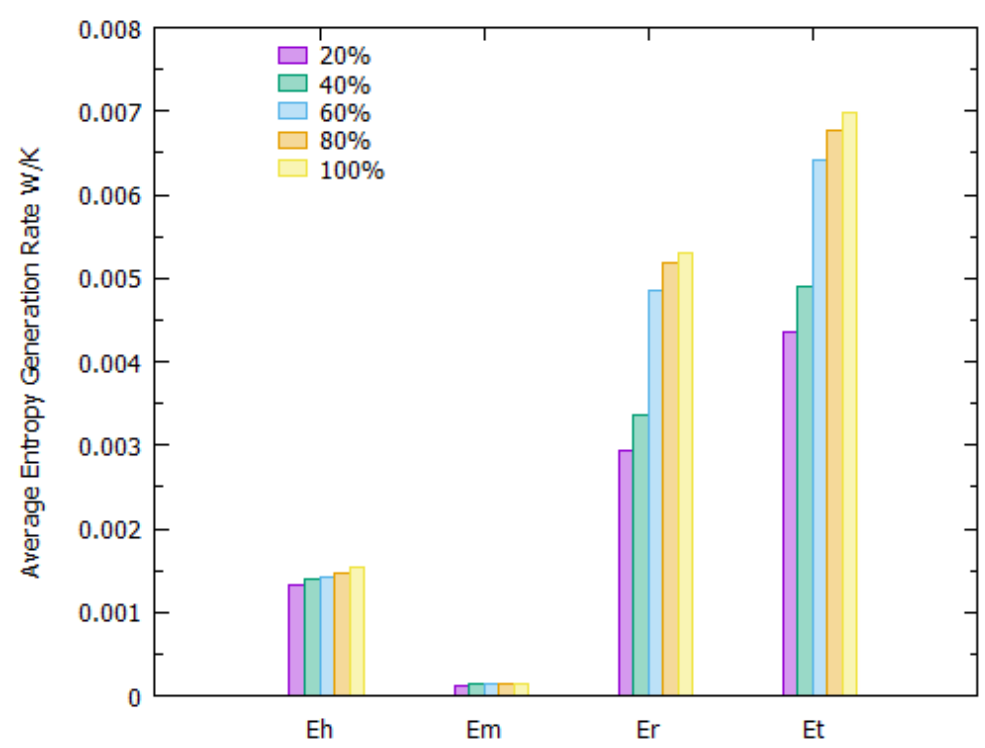

Fig. 14: Global entropy generation rate for varying concentrations of oxygen, calculated for $200 \mathrm{~ms}$, a) active flow, b) quiescent flow. 